\title{
Expansão e impactos socioambientais da cultura de Eucalyptus spp. (Myrtaceae) no Brasil: um panorama da literatura
}

\author{
Expansion and socio-environmental impacts of the culture of Eucalyptus spp. (Myrtaceae) in
}

Brazil: a literature panorama

Expansión e impactos socioambientales de la cultura de Eucalyptus spp. (Myrtaceae) en Brasil: una visión general de la literatura

\author{
Ritielly Maria Guimarães Guerino \\ ORCID: https://orcid.org/0000-0003-0662-6154 \\ Universidade Estadual de Goiás, Brasil \\ E-mail: bioguerino@gmail.com \\ Isa Lucia de Morais \\ ORCID: https://orcid.org/0000-0001-8748-9723 \\ Universidade Estadual de Goiás, Brasil \\ E-mail: isamorais1@gmail.com \\ Aline Bezerra da Silva Santos \\ ORCID: https://orcid.org/0000-0001-6875-5934 \\ Universidade Federal de Goiás, Brasil \\ E-mail: alinebezerradasilvasantos@gmail.com \\ Renata Martins Campos \\ ORCID: https://orcid.org/0000-0002-5177-3009 \\ Universidade Estadual de Goiás, Brasil \\ E-mail: rmcamposbio@hotmail.com
}

\begin{abstract}
Resumo
No Brasil Eucalyptus tem sido um gênero muito cultivado por apresentar características comerciais desejáveis, haja vista que da maioria das espécies se aproveita a celulose, madeira e óleos essenciais. Assim, este estudo objetivou realizar uma compilação de dados acerca da expansão da eucaliptocultura no Brasil na última década e seus impactos socioambientais. Foi realizada uma revisão da literatura mediante consulta de livros e artigos científicos das bases eletrônicas Scielo, Periódicos CAPES e EBSCO Discovery Service (EDS). A demanda do mercado externo nos últimos 20 anos posicionou o Brasil em patamares elevados no contexto mundial de produção de celulose e fez com que houvesse uma grande expansão da área plantada de eucalipto no Brasil na última década. As atividades das fases de implantação, manutenção e colheita da eucaliptocultura, resultam em modificações das condições socioambientais outrora existente no local. Entre os impactos benéficos está a contribuição positiva à economia nacional, pois, gera um incremento comercial, com produtos de consumo interno e para exportação, impostos e empregos para a população. Entre os impactos adversos estão o empobrecimento da biodiversidade local, degradação ambiental e conflitos no meio rural e urbano. Para minimizar esses impactos adversos é necessária a implementação de uma gestão ambiental ecologicamente correta, com a identificação das características e condições de conservação ambientais locais (como, proximidade de áreas de vegetação ripária, biodiversidade local, tipos de clima e solo, declividade do terreno, disponibilidade hídrica da bacia hidrográfica), da estrutura fundiária pré-existente e implementação de um conjunto de ações mitigadoras para cada impacto adverso.
\end{abstract}

Palavras-chave: Biodiversidade; Espécie exótica; Eucaliptocultura; Monocultura.

\begin{abstract}
In Brazil Eucalyptus has been a very cultivated genus because it has desirable commercial characteristics, considering that cellulose, wood and essential oils are used in most species. Thus, this study aimed to compile data on the expansion of eucalyptus culture in Brazil in the last decade and its socio-environmental impacts. A literature review was carried out by consulting books and scientific articles from the electronic databases Scielo, Periodicals CAPES and EBSCO Discovery Service (EDS). Over the last 20 years, the demand from the foreign market has positioned Brazil at high levels in the world context of pulp production and has led to a great expansion of the eucalyptus planted area in Brazil in the last decade. The activities of the implantation, maintenance and harvesting phases of the eucalyptus crop, result in changes in the socio-environmental conditions that used to exist in the place. Among the beneficial impacts is the positive contribution to the national economy, as it generates an increase in trade, with products for domestic consumption and for export, taxes and jobs for the population. Among the adverse impacts are
\end{abstract}


the impoverishment of local biodiversity, environmental degradation and conflicts in rural and urban areas. To minimize these adverse impacts, it is necessary to implement ecologically correct environmental management, with the identification of local environmental conservation characteristics and conditions (such as proximity to riparian vegetation areas, local biodiversity, types of climate and soil, terrain slope, water availability in the hydrographic basin), the pre-existing land structure and implementation of a set of mitigating actions for each adverse impact.

Keywords: Biodiversity; Exotic species; Eucalyptusculture; Monoculture.

\section{Resumen}

En Brasil, Eucalyptus ha sido un género muy cultivado porque tiene características comerciales deseables, considerando que la celulosa, la madera y los aceites esenciales se utilizan en la mayoría de las especies. Por lo tanto, este estudio tuvo como objetivo recopilar datos sobre la expansión del cultivo de eucalipto en Brasil en la última década y sus impactos socioambientales. Se realizó una revisión bibliográfica consultando libros y artículos científicos de las bases de datos electrónicas Scielo, Periódicos CAPES y EBSCO Discovery Service (EDS). En los últimos 20 años, la demanda del mercado externo ha posicionado a Brasil en niveles altos en el contexto mundial de la producción de celulosa y ha llevado a una gran expansión del área plantada de eucalipto en Brasil en la última década. Las actividades de las fases de implantación, mantenimiento y cosecha del cultivo de eucalipto, resultan en cambios en las condiciones socioambientales que existían en el lugar. Entre los impactos benéficos está el aporte positivo a la economía nacional, ya que genera un incremento en el comercio, con productos para consumo interno y para exportación, impuestos y empleo para la población. Entre los impactos adversos están el empobrecimiento de la biodiversidad local, la degradación ambiental y los conflictos en áreas rurales y urbanas. Para minimizar estos impactos adversos, es necesario implementar un manejo ambiental ecológicamente correcto, con la identificación de las características y condiciones locales de conservación ambiental (como proximidad a áreas de vegetación ribereña, biodiversidad local, tipos de clima y suelo, pendiente del terreno, disponibilidad de agua en la cuenca hidrográfica), la estructura territorial preexistente y la implementación de un conjunto de acciones mitigadoras para cada impacto adverso.

Palabras clave: Biodiversidad; Especies exoticas; Cultivo de eucalipto; Monocultivo.

\section{Introdução}

O gênero Eucalyptus L'Hér. pertence à família Myrtaceae e é nativo da Austrália (Lino et al., 2020), apresentando uma grande variedade de espécies e híbridos (Ramalho et al., 2020). O cultivo mundial de Eucalyptus tem crescido significativamente por apresentar muitas características comerciais desejáveis, uma vez que dele tudo se aproveita: a celulose para a produção de papel, madeira para a produção de energia, móveis, chapas, construções de casas e óleos essenciais usados de variadas formas na indústria farmacêutica, cosmética entre outras (Bertola, 2013; Kudlavicz, 2014; Moledo et al., 2016; Ferreira et al., 2017; Cabral et al., 2019; Correa et al., 2020a; Ramalho et al., 2020; Teago et al., 2020; Teixeira et al., 2020; IBÁ, 2021; Monteiro et al., 2021).

Com a expansão da produção do eucalipto, esse táxon passou a ser tema de debates entre ambientalistas e os que se dedicaram à sua produção. As opiniões se dividem consoante aos interesses e ao nível de conhecimento a respeito do tema (Lima, 1996; Scolforo, 2008; Moledo et al., 2016; Teixeira et al., 2020; Amorim et al., 2021; Rodrigues et al., 2021; Souza et al., 2021).

A produção de eucalipto em larga escala tem como pontos positivos a preservação de florestas nativas para a obtenção de produtos de base florestal (Costa et al., 2020; Medeiros et al., 2020; Teixeira \& Rodrigues, 2021). Com o crescimento constante da população humana, o uso de produtos como madeira, celulose, carvão vegetal, óleos e energia também são crescentes (Cabral et al., 2019; Barros et al., 2020; Bichel et al., 2021; IBÁ, 2021; Teixeira et al., 2021). As árvores de eucalipto contribuem de forma positiva com o processo de recuperação de solos exauridos e com absorção de $\mathrm{CO}_{2}$ da atmosfera, diminuindo a poluição e o calor. A geração de produtos de consumo interno e para exportação, impostos e empregos para a população, são pontos positivos da monocultura em relação à economia (Vital, 2007; Costa et al., 2019; Correa et al., 2020a; Correa et al., 2020b; Medeiros et al., 2020; Teixeira et al., 2020).

Por outro lado, existem pesquisas que abordam os prejuízos ao ambiente com a introdução de uma monocultura de eucalipto. Na implantação da eucaliptocultura os problemas ocorrem desde a preparação da área para plantio, devido à 
utilização de maquinário pesado que causa a compactação do solo, comprometendo a infiltração da água destinada aos lençóis freáticos, uso de insumos agrícolas, desbaste de áreas e construção de estradas (Barbieri et al., 1997; Moledo et al., 2016; Ebling et al., 2021). Com a monocultura de eucalipto já estabelecida os problemas estão relacionados ao consumo demasiado de água e nutrientes, alterações nas propriedades do solo e redução da biodiversidade de fauna e flora com os efeitos alelopáticos. A retirada dos indivíduos de eucalipto também acarreta danos ao ambiente, haja vista que com o primeiro corte raso o solo fica desprotegido, provocando o aumento da temperatura e maior impacto da água da chuva no solo, evento que favorece os processos de erosão (Tucci et al., 1997; Moledo et al., 2016).

Com exceção da Austrália, em todos os outros países onde é plantado, o eucalipto é uma espécie exótica, sendo, que, na maioria das vezes, o plantio ocorre principalmente na forma de monoculturas extensas, as quais apresentam baixa diversidade ecológica (Lima, 1996; Moledo et al., 2016; Rodrigues et al., 2021). Isso poderia resultar em instabilidade ou vulnerabilidade a mudanças climáticas, assim como ao ataque de pragas e doenças (Fernandes et al., 2021). A ocorrência de compostos alelopáticos, principalmente nas folhas, é outro ponto preocupante. Esses compostos prejudicam o desenvolvimento de outras plantas e dificultam o processo de decomposição microbiológica dos resíduos (Silva et al., 2004). As folhas de eucalipto dispersas na serapilheira, durante o período de chuvas, são levadas para rios e lagoas através da lixiviação, e, entrando em contato com o ambiente aquático, liberam constituintes químicos, como os do óleo essencial. A prevalência desses compostos no meio aquoso representa um risco potencial de efeitos prejudiciais aos organismos aquáticos (Abelho et al., 1996).

A partir deste contexto, de perspectivas contraditórias acerca dos impactos da eucaliptocultura, o presente estudo objetivou realizar uma compilação de dados com subsídio em estudos acerca da expansão do eucalipto no Brasil, em especial na última década, e seus impactos socioambientais.

\section{Material e Métodos}

Esta pesquisa consiste em uma revisão sistemática de literatura, mediante uma ampla busca na literatura, agregando sistematicamente informações específicas por meio do mapeamento e avaliação dos estudos existentes, identificando lacunas e ampliando a possibilidade para novos estudos (Salim et al., 2019; Aires et al., 2020). Ela apresenta caráter bibliográfico do tipo estado do conhecimento (Morosini, 2015), almejando mapear e discutir a produção acadêmica sobre a eucaliptocultura quanto à expansão no Brasil, em especial, na última década (2010-2021), e os impactos socioambientais oriundos desta atividade.

O levantamento bibliográfico foi feito mediante consultas a livros, sites de instituições públicas e privadas ligadas ao setor da eucaliptocultura, periódicos e artigos científicos, através das bases eletrônicas Scielo, Google scholar e Portal de Periódicos CAPES com filtro para coleção Scopus e EBSCO.

A pesquisa dos artigos foi realizada na base de dados eletrônica de periódico CAPES, por apresentar um número expressivo de revista e acesso gratuito à base de dados. A seleção dos artigos foi realizada com filtro para base Web of Science. Para a busca foram utilizadas as palavras Eucalyptus* expansion* Brazil, para seleção de artigos sobre a expansão da produção de eucalipto no Brasil, e, Eucalyptus* impact* Brazil, para os que abordam sobre os impactos da produção de eucalipto no Brasil. A busca e o critério de inclusão abrangeram essas palavras juntas, pois os termos separados incluem uma variedade de trabalhos que estão fora do contexto da presente pesquisa.

Os critérios de inclusão foram pesquisas publicadas no período de 2010 a 2021, no idioma português, inglês e espanhol, que atendiam o objetivo da pesquisa. As áreas selecionadas no filtro foram: silvicultura, ciências ambientais, ciências do solo, agronomia, conservação da biodiversidade, ecologia, agricultura multidisciplinar, estudos ambientais e recursos hídricos. Os critérios de exclusão foram trabalhos científicos com apenas resumos disponíveis, publicações duplicadas, artigos de relato de experiência, reflexivo e editoriais. Foram lidos os resumos e palavras-chaves e aplicados os critérios de inclusão e 
exclusão, resultando na seleção dos artigos que vinham de encontro ao interesse da pesquisa.

\section{Resultados e Discussão}

A Figura 1 apresenta um fluxograma sobre o processo de seleção das publicações, no qual mostra a diminuição na quantidade de artigos à medida que ocorreu a filtragem para o levantamento dos artigos sobre a expansão e impactos da eucaliptocultura no Brasil.

Figura 1. Fluxograma sobre o processo de seleção das publicações sobre a expansão e impactos da eucaliptocultura no Brasil entre 2010 e 2021.

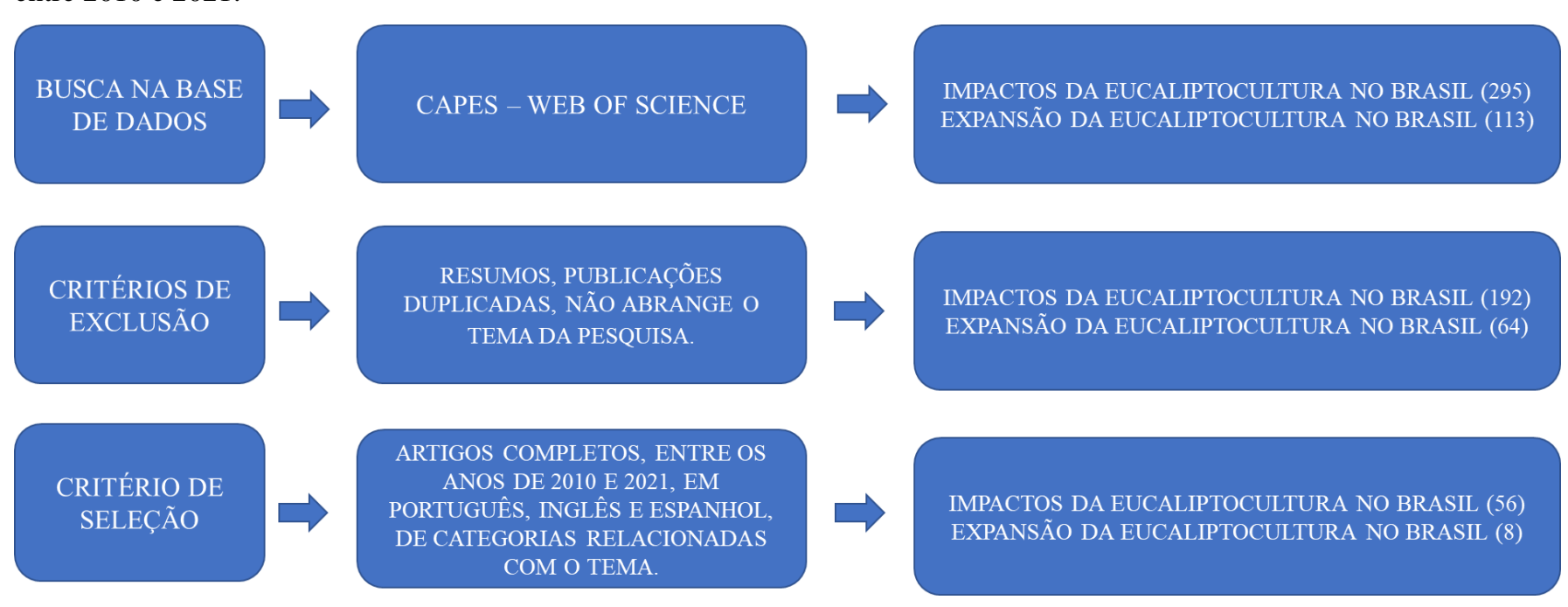

Fonte: Autores.

Para a busca de trabalhos sobre a expansão da produção de eucaliptos, foram encontrados 73 artigos. Após a aplicação dos critérios foram selecionados 64 artigos para análise, destes 56 foram descartados por não se enquadrarem no tema proposto. Para a busca de trabalhos sobre os impactos da produção de eucalipto, foram encontrados 295 artigos, após a aplicação dos critérios foram selecionados 192 trabalhos para análise dos resumos e palavras-chave, 136 foram excluídos por não enquadrem no tema. $\mathrm{O}$ resultado foi a seleção de 8 artigos que abordam sobre a expansão da produção de eucalipto (em destaque verde no Quadro 1) e 56 sobre os impactos da produção do eucalipto no Brasil. Vale ressaltar, que os resultados e discussão foram construídos subsidiados por outras fontes além dos mencionados no Quadro 1 e nem todos os artigos incluídos neste quadro foram usados nos resultados e discussão. 
Quadro 1. Dados dos artigos selecionados para a pesquisa entre 2010 e 2021, sendo oito sobre a expansão da produção de eucalipto (em destaque verde) e 56 sobre os impactos da produção do eucalipto no Brasil, seguindo a ordem cronológica de publicação.

\begin{tabular}{|c|c|c|}
\hline Autor(es) & Ano & Objetivo(s) \\
\hline Afonso, R; Miller, DC & 2021 & $\begin{array}{c}\text { Analisar os impactos socioeconômicos das plantaç̃os florestais em todos os municípios mineiros, estado com } \\
\text { maior área de plantio do Brasil desde } 1980 .\end{array}$ \\
\hline Bichel, A; Telles, TS & 2021 & $\begin{array}{l}\text { Verificar se a expansão das culturas florestais, principalmente de eucalipto, mudou a dinâmica estrutural e } \\
\text { espacial da produção de carvão vegetal e lenha no Brasil. }\end{array}$ \\
\hline $\begin{array}{l}\text { Medeiros, G; Florindo, T; Talamini, } \\
\text { E; Fett, A; Ruviaro, C }\end{array}$ & 2020 & $\begin{array}{l}\text { Comparar o desempenho ambiental e econômico dos sistemas de produção florestal de pinheiros e eucaliptos } \\
\text { para múltiplas finalidades visando uma alocação otimizada do uso da terra na Região Centro-Oeste do Brasil. }\end{array}$ \\
\hline $\begin{array}{l}\text { Lenz, AM; Rosa, HA; Mercante, E; } \\
\text { Maggi, MF; Mendes, ID; Cattani, } \\
\text { CEV; Johann, JA; Ferruzzi, Y; } \\
\text { Gurgacz, F }\end{array}$ & 2019 & $\begin{array}{l}\text { Explorar a expansão das plantações de eucalipto em um cenário de LFI para agroindústrias no Oeste do Paraná, } \\
\text { Brasil, e estimar a área com potencial de expansão da agricultura por meio de imagens de satélite Landsat-8. }\end{array}$ \\
\hline $\begin{array}{l}\text { Brockerhoff, EG; Jactel, H; } \\
\text { Parrotta, JA; Ferraz, SFB }\end{array}$ & 2013 & $\begin{array}{l}\text { Avaliar os efeitos na biodiversidade florestal e na prestação de serviços ecossistêmicos através de uma revisão } \\
\text { sobre as tendências recentes de desmatamento, arborização e reflorestamento. }\end{array}$ \\
\hline $\begin{array}{l}\text { Rezende, JB; Pereira, JR; Botelho, } \\
\text { DD }\end{array}$ & 2013 & $\begin{array}{l}\text { Analisar o desenvolvimento do índice de monocultura do eucalipto como elemento-chave para a gestão do } \\
\text { território, na perspectiva do desenvolvimento sustentável. }\end{array}$ \\
\hline $\begin{array}{l}\text { Oberling, DF; La Rovere, EL; Silva, } \\
\text { HVD }\end{array}$ & 2013 & $\begin{array}{l}\text { Apresentar a estrutura e os resultados do MAR dos planos de expansão da silvicultura de eucalipto e } \\
\text { biocombustíveis na Região Extremo Sul da Bahia, no Nordeste brasileiro, em um contexto de planejamento } \\
\text { setorial dissociado das diretrizes governamentais para a política de uso da terra e proteção ambiental. }\end{array}$ \\
\hline $\begin{array}{c}\text { Maire, G le; Marsden, C; } \\
\text { Nouvellon, Y; Grinand, C; } \\
\text { Hakamada, R; Stape, JL; Laclau, JP }\end{array}$ & 2011 & $\begin{array}{l}\text { Avaliar as informações sobre a estrutura do dossel englobadas em séries temporais de refletância do estande, } \\
\text { com uso da base do Índice de Vegetação de Diferença Normalizada após um procedimento envolvendo un- } \\
\text { mixing e interpolação, em cerca de } 15.000 \text { ha de plantações de eucalipto no sul do Brasil. }\end{array}$ \\
\hline $\begin{array}{l}\text { Souza, NRD de; Junqueira, TL; } \\
\text { Cavalett, O }\end{array}$ & 2021 & $\begin{array}{l}\text { Avaliar comparativamente as oportunidades da integração bioenergia-pecuária no Brasil para entender melhor as } \\
\text { questões de sustentabilidade das alternativas de integração dessas cadeias de valor, destacando os principais } \\
\text { aspectos tecnoeconômicos e ambientais. }\end{array}$ \\
\hline $\begin{array}{l}\text { Ferraz, SFB; Rodrigues, CB; } \\
\text { Garcia, LG; Pena-Sierra, D; } \\
\text { Fransozi, A; Ogasawara, MEK; } \\
\text { Vasquez, K; Moreira, RM; } \\
\text { Cassiano, CC }\end{array}$ & 2021 & $\begin{array}{l}\text { Realizar uma compilação dos resultados de alguns estudos do centro de monitoramento hidrológico da Estação } \\
\text { Florestal Experimental de Itatinga, da Universidade de São Paulo, no qual o monitoramento hidrológico } \\
\text { começou em 1987, e atualmente inclui três captações ( } 83-98 \text { ha) em diferentes regimes de manejo florestal: } \\
\text { plantio de eucalipto de curto rotação, mosaico de plantações florestais de longo prazo e restauração de florestas } \\
\text { nativas. }\end{array}$ \\
\hline $\begin{array}{l}\text { Morais, JR de; Castilhos, RMV; } \\
\text { Lacerda, CL; Pinto, LFS; Carlos, FS }\end{array}$ & 2021 & $\begin{array}{l}\text { Avaliar as mudanças no carbono do solo, nitrogênio e suas frações labiais e atributos microbiológicos do solo } \\
\text { devido à introdução do cultivo de eucalipto no bioma Pampa. }\end{array}$ \\
\hline $\begin{array}{l}\text { Ebling, ED; Reichert, JM; Pelaez, } \\
\text { JJZ; Rodrigues, MF; Valente, ML; } \\
\text { Cavalcante, RBL; Reggiani, P; } \\
\text { Srinivasan, R }\end{array}$ & 2021 & $\begin{array}{l}\text { Avaliar a hidrologia e sedimentação baseadas em eventos em bacias hidrográficas emparelhadas sob cobertura } \\
\text { comercial de eucalipto e pastagens. }\end{array}$ \\
\hline $\begin{array}{c}\text { Ferreto, DOC; Reichert, JM; } \\
\text { Cavalcante, RBL; Srinivasan, R }\end{array}$ & 2021 & $\begin{array}{l}\text { Investigar os efeitos das plantações de Eucalyptus spp. sobre fluxos orçamentários de água no bioma das } \\
\text { pastagens do sul do Brasil. }\end{array}$ \\
\hline $\begin{array}{l}\text { Zolin, CA; Matos, ED; Magalhaes, } \\
\text { CAD; Paulino, J; Lal, R; Spera, ST; } \\
\text { Behling, M }\end{array}$ & 2021 & $\begin{array}{l}\text { Avaliar a floresta agropecuária integrada (ICLF) como um sistema de manejo agrícola sustentável para a região } \\
\text { ecótone Cerrado-Amazônia. }\end{array}$ \\
\hline Fiorese, $\mathrm{CHU}$ & 2021 & $\begin{array}{l}\text { Avaliar o uso e ocupação do solo na sub-bacia do Córrego Fundaga, estado do Espírito Santo, Brasil, visando } \\
\text { subsidiar melhorias na conservação ambiental e no planejamento territorial. }\end{array}$ \\
\hline $\begin{array}{l}\text { Oliveira, FCC; Ferreira, GWD; } \\
\text { Santos, RS; Aubrey, DP; Araujo, } \\
\text { EF; Silva, IR }\end{array}$ & 2021 & $\begin{array}{l}\text { Avaliar as mudanças no efluxo de } \mathrm{CO}_{2} \text { do solo - um proxy para a respiração do solo - por três anos após uma } \\
\text { conversão de pastagens nativas para plantações de eucalipto no sul do Brasil, onde o preparo mínimo durante a } \\
\text { preparação do local criou duas zonas distintas do solo, dentro da linha de plantio e na entrelinha. }\end{array}$ \\
\hline $\begin{array}{l}\text { Medeiros, AD; Ferraz, RLD; da } \\
\text { Silva, TS; da Silva, AVL; Maia, } \\
\text { SMF }\end{array}$ & 2021 & $\begin{array}{c}\text { Avaliar os efeitos da conversão de áreas cultivadas com cana-de-açúcar para plantações de Eucalyptus spp. sobre } \\
\text { a qualidade do solo e o sequestro de carbono em um Latossolo na região da Mata Atlântica do estado de } \\
\text { Alagoas, Brasil, por meio de análise multivariada. }\end{array}$ \\
\hline $\begin{array}{l}\text { Gualberto, AVS; da Cunha, JR; } \\
\text { Vogado, RF; Leite, LFC; Nunes, } \\
\text { LAPL; de Souza, HA }\end{array}$ & 2021 & $\begin{array}{l}\text { Avaliar a densidade e diversidade da macrofauna do solo e os grupos funcionais da macrofauna epigeal que são } \\
\text { mais representativos em sistemas de plantio direto, pastagem, cultivo de eucalipto e savana nativa em Urugui, } \\
\text { Piauí, Brasil. }\end{array}$ \\
\hline $\begin{array}{l}\text { Sena, KN; Maltoni, KL; Troleis, } \\
\text { MJB; Faria, GA }\end{array}$ & 2021 & $\begin{array}{l}\text { Investigar as mudanças no teor total de carbono orgânico e seu efeito sobre propriedades físicas em áreas sob } \\
\text { diferentes sistemas de manejo de colheita (HMS) após a colheita de eucalipto. }\end{array}$ \\
\hline $\begin{array}{l}\text { Amaral, PHM do; Peixoto, SD; } \\
\text { Machado, MMD; Rocha, CHB; } \\
\text { Alves, RD }\end{array}$ & 2020 & $\begin{array}{c}\text { Verificar se a composição granulométrica do sedimento da nascente em áreas florestais difere da das nascentes } \\
\text { em áreas plantadas com eucalipto. }\end{array}$ \\
\hline $\begin{array}{l}\text { Medeiros, G; Florindo, T; Talamini, } \\
\text { E; Fett, A; Ruviaro, C }\end{array}$ & 2020 & $\begin{array}{l}\text { Comparar o desempenho ambiental e econômico dos sistemas de produção florestal de pinheiros e eucaliptos } \\
\text { para múltiplas finalidades visando uma alocação otimizada do uso da terra na Região Centro-Oeste do Brasil. }\end{array}$ \\
\hline $\begin{array}{l}\text { Falcao, KD; Panachuki, E; } \\
\text { Monteiro, FD; Menezes, RD; } \\
\text { Rodrigues, DBB; Sone, JS; } \\
\text { Oliveira, PTS } \\
\end{array}$ & 2020 & $\begin{array}{l}\text { Avaliar o escoamento da superfície e a perda de solo em uma área de cerrado florestal sob uma antiga área de } \\
\text { pastagem, que foi abandonada e passou por um processo de regeneração natural por } 7 \text { anos. }\end{array}$ \\
\hline $\begin{array}{c}\text { Valente, ML; Reichert, JM; Legout, } \\
\text { C; Tiecher, T; Cavalcante, RBL; } \\
\text { Evrard, O }\end{array}$ & 2020 & $\begin{array}{l}\text { Calcular as contribuições relativas das fontes de sedimentos em duas bacias em pares, uma com plantações } \\
\text { comerciais de eucalipto e outra com pastagens utilizadas para pecuária, no Pampa brasileiro, utilizando } \\
\text { diferentes combinações de propriedades convencionais (geoquímicas, radionuclídeos e isótopos estáveis e } \\
\text { propriedades de matéria orgânica) e propriedades de rastreador alternativos (parâmetros de cores de base visível } \\
\text { espectrítricas). }\end{array}$ \\
\hline
\end{tabular}


Hatfield, JH; Barlow, J; Joly, CA; Lees, AC; Parruco, CHD; Tobias, JA; Orme, CDL; Banks-Leite, C

Lopez-Poma, R; Pivello, VR; de Brito, GS; Bautista, S

Brancalion, PHS; Amazonas, NT; Chazdon, RL; van Melis, J;

Rodrigues, RR; Silva, CC; Sorrini, TB; Holl, KD

Borges, WLB; Calonego, JC; Rosolem, CA

Ferraz, SFD; Rodrigues, CB;

Garcia, LG; Alvares, CA; Lima, WD

Garren, AM; Bolding, MC; Aust, WM; Moura, AC; Barrett, SM

Tassinari, D; Andrade, MLD; Dias, MD; Martins, RP; Rocha, WW; Pais, PSAM; de Souza, ZR

Jacoboski, LI; Luza, AL; Paulsen, RK; Pezda, AM; Hartz, SM

Maillard, F; Leduc, V; Bach, C; Goncalves, JLD; Androte, FD; Saint-Andre, L; Laclau, JP; Buee, M; Robin, A

Brito, GS de; Bautista, S; LopezPoma, R; Pivello, VR

Valadao, MBX; Carneiro, KMS; Inkotte, J; Ribeiro, FP; Miguel, EP; Gatto, A

Camara, R; Silva, VD; Correia, MEF; Villela, DM

Jacoboski, LI; Luza, AL; Paulsen, RK; Pezda, AM; Hartz, SM

\begin{tabular}{c} 
Gainsbury, AM; Colli, GR \\
\hline $\begin{array}{c}\text { Cavalett, O; Slettmo, SN; } \\
\text { Cherubini, F }\end{array}$ \\
\hline $\begin{array}{c}\text { Garcia, LG; Salemi, LF; Lima, WD; } \\
\text { Ferraz, SFD }\end{array}$ \\
\hline
\end{tabular}

Rosa, MG da; Santos, JCP; Brescovit, AD; Mafra, AL; Baretta, D

Silva, ER da; da Silveira, LHR; Overbeck, GE; Soares, GLG Gardiman, BS; Garcia, GD; Cecilio, RA; Loos, RA; Mafia, RG; Abad, JIM; Simao, JBP; Barbosa, VHB

\section{Rodrigues, TF; Chiarello, AG}

Queiroz, ACM de; Rabello, AM; Braga, DL; Santiago, GS; Zurlo, LF; Philpott, SM; Ribas, CR

Zanzini, ACD; Silva, AAN; Pereira, CZ; Santiago, WTV; Zanon, MHD

Fantini, AC; Bauer, E; de Valois, CM; Siddique, I

Machado, DD; Costa, EC; Pedron, $\mathrm{L}$
Avaliar os efeitos do tipo matricial na biodiversidade em 49 locais diferentes com diferentes níveis de fragmentação da paisagem na Mata Atlântica brasileira - um ponto de acesso de biodiversidade altamente ameaçado - nas espécies de aves em um gradiente de matriz interior.

Investigar os efeitos da conversão do cerrado florestal (cerradão) em pastagens e plantações de eucalipto sobre 2020 disponibilidade de nitrogênio e potencial de mineralização, considerando uma ampla gama de temporalidade espacial e variação devido à profundidade do solo, condições do local e variação sazonal.

Avaliar os impactos da incorporação de eucaliptos exóticos como etapa de transição na restauração de florestas tropicais no acúmulo de biomassa acima do solo, regeneração de espécies nativas e viabilidade financeira ao longo de 7 anos de estudos experimentais em três locais de Mata Atlântica.

2019 Avaliar as propriedades químicas e físicas do solo em um sistema agroflorestal à base de eucalipto.

Analisar o uso de água por plantações de Eucalipto no Brasil com base em dados de fluxo e precipitação de 19 2019 captações instrumentadas nas quais as plantações de Eucalipto ocupam mais que 50\% da área terrestre e onde os registros se estendem de 2 a 15 anos (120 anos de dados).

2019 Quantificar as mudanças nas propriedades do solo e prever a erosão resultante de vários números de passes e níveis de carga por um atacante operando em encostas que variam de 27 a 38 graus.

Avaliar o impacto na estrutura do solo de diferentes maquinários em alguns solos de textura grossa (Argissolos e Espodossolos arenosos a franco-argilosos) do Nordeste do Brasil.

Investigar se a conversão de pastagens nativas em plantações florestais impactou a diversidade evolutiva e taxonômica das comunidades de aves, através de uma análise das diferentes dimensões da diversidade.

Avaliar os efeitos do manejo de resíduos de colheita (galhos, folhas, cascas) de árvores de Eucalyptus grandis em atividades enzimáticas do solo e perfis fisiológicos de nível comunitário em uma plantação brasileira.

Avaliar comparativamente o impacto da mudança do uso da terra nas piscinas labile e na dinâmica do carbono orgânico do solo em dois usos terrestres (pastagens de Urochloa e florestas de eucalipto) em relação ao ecossistema de referência nativa (cerradão), em função da profundidade e estação do solo.

Avaliar a queda de lixo, a camada de lixo e a decomposição das folhas na plantação de eucalipto com 60 meses de idade na região do Cerrado, Distrito Federal.

Avaliar os efeitos da remoção da camada de lixo na comunidade de artrópodes do solo em duas plantações abandonadas de Corymbia citriodora em diferentes estágios da regeneração natural de Mata Atlântica.

Investigar a eficácia de pastagens legalmente protegidas em terras privadas para proteger aves em "Associações de aves campestres em áreas protegidas e não protegidas no sul do Brasil" [1] e também os efeitos da arborização de pastagens sobre diferentes dimensões da diversidade de aves em "Os efeitos da florestação do ecossistema de pastagem na diversidade filogenética, diversidade taxonômica e distinção evolutiva de aves" [2].

Testar, através de índices de estrutura de comunidade filogenética, se os processos potenciais de formação de comunidades de lagartos diferem entre habitats não perturbados do Cerrado e plantações abandonadas de $2019 \begin{aligned} & \text { eucalipto perturbadas; e em caso afirmativo, se esses processos são previsíveis. Além disso, testar a } \\ & \text { aplicabilidade de índices de estrutura de comunidades filogenéticas como indicadores ecológicos de distúrbios }\end{aligned}$ antropogênicos no hotspot de biodiversidade do Cerrado.

2018 Comprovar que todos os sistemas de bioenergia podem alcançar benefícios climáticos consideráveis, mas em alguns casos com maior pressão em outras categorias de impacto.

2018 Avaliar a influência de plantações florestais na vazão em uma bacia calibrada coberta por plantações de Eucalyptus sp. de rápido crescimento.

Avaliar a diversidade de aranhas em diferentes sistemas de uso do solo com captura por dois métodos de

2018 amostragem e identificar propriedades do solo que possam modular a ocorrência de aranhas.

2018 Investigar os efeitos do lixo da folha de Eucalyptus saligna na colonização e desenvolvimento da camada terrestre por espécies de pastagens e se esses efeitos estavam relacionados à allelopatia.

Identificar as principais variáveis afetadas por fatores naturais e, ou, antrópicos, que influenciam a qualidade da água superficial em microbacias hidrográficas, manejadas para produção de madeira de eucalipto.

Avaliar os efeitos relativos das características paisagísticas, composição e configuração, impactos 2018 antropogênicos e grau de proteção, como potenciais preditores de ocupação paisagística do tatu-de-nove-bandas (Dasypus novemcinctus).

Avaliar como a conversão de três tipos de vegetação nativa do Cerrado (pastagens abertas, savana típica e savana florestal) para dois usos de terras manejados pelo homem (plantações e pastagens de eucalipto) afeta a riqueza e a composição das formigas em comunidades arbóreas, epigaílicas e hipogagéicas.

Avaliar a composição de espécies das comunidades de mamíferos de médio e grande porte em plantações de eucalipto e fragmentos de florestas nativas em um projeto florestal no sudeste do Estado de Minas Gerais.

Avaliar a mudança da cobertura da terra e do uso da terra em uma bacia hidrográfica onde o cultivo de corte e 2017 queima eram predominantes, visando compreender os fatores de mudança e discutir impactos passados e futuros, incluindo a percepção dos agricultores sobre os fatores de mudança de uso da terra.

Avaliar a composição da mesofauna do solo em áreas não mineradas e mineradas, sob recuperação ambiental com vegetação nativa e silvicultura, em mina de carvão mineral no Sul do Brasil. 


\begin{tabular}{|c|c|c|}
\hline $\begin{array}{l}\text { Tonucci, RG; Nair, VD; Nair, PKR; } \\
\text { Garcia, R }\end{array}$ & 2017 & $\begin{array}{l}\text { Quantificar as contribuições relativas de carbono orgânico do solo das plantas C3 e C4 em diferentes sistemas de } \\
\text { uso da terra. }\end{array}$ \\
\hline $\begin{array}{l}\text { Ferreira, GB; Ahumada, JA; } \\
\text { Oliveira, MJR; de Pinho, FF; } \\
\text { Barata, IM; Carbone, C; Collen, B }\end{array}$ & 2017 & $\begin{array}{l}\text { Avaliar o efeito da vegetação secundária em grandes mamíferos em uma área protegida do Cerrado brasileiro, } \\
\text { usando uma estrutura de ocupação de estação única para investigar a resposta de espécies individuais (modelos } \\
\text { em nível de espécie) e de todas as espécies combinadas (modelos de nível comunitário) e investigar a relação } \\
\text { custo-benefício de diferentes desenhos de amostragem para monitorar espécies globalmente ameaçadas na área } \\
\text { de estudo. }\end{array}$ \\
\hline $\begin{array}{c}\text { Reichert, JM; Rodrigues, MF; } \\
\text { Pelaez, JJZ; Lanza, R; Minella, } \\
\text { JPG; Arnold, JG; Cavalcante, RBL }\end{array}$ & 2017 & $\begin{array}{l}\text { Avaliar a influência da cobertura vegetal nos processos hidrológicos, descrevendo o equilíbrio hídrico e seus } \\
\text { componentes (chuvas, interceptação, queda, evapotranspiração real, recarga de águas subterrâneas e fluxo de } \\
\text { córregos) em duas bacias hidrográficas emparelhadas. }\end{array}$ \\
\hline $\begin{array}{l}\text { Andrade, MLD; Tassinari, D; Dias, } \\
\text { MD; Martins, RP; Rocha, WW; de } \\
\text { Souza, ZR }\end{array}$ & 2017 & $\begin{array}{c}\text { Avaliar a capacidade de suporte de carga de solos de textura grosseira (dois Hapludult e um Haplorthod) em } \\
\text { dois horizontes (BA e B) do Nordeste do Brasil; além de avaliar o impacto das operações de colheita e baldeio de } \\
\text { madeira realizadas com harvester e forwarder. }\end{array}$ \\
\hline $\begin{array}{l}\text { Pompeo, PN; de Oliveira, LCI; dos } \\
\text { Santos, MAB; Mafra, AL; } \\
\text { Klauberg, O; Baretta, D }\end{array}$ & 2017 & $\begin{array}{l}\text { Amostrar a diversidade de coleópteros, utilizando uma metodologia de características ecomorfológicas, bem } \\
\text { como sua relação com os sistemas de uso da terra (LUS) e as propriedades do solo. }\end{array}$ \\
\hline $\begin{array}{l}\text { Ganba, OS; Tonello, KC; Garcia- } \\
\text { Leite, H; Burguet, M; Taguas, EV; } \\
\text { Teixeira-Dias, HC }\end{array}$ & 2016 & $\begin{array}{l}\text { Avaliar a precipitação, interceptação e evapotranspiração das plantações de eucalipto na escala de captação por } \\
\text { um período de mais de } 2 \text { anos (2008-2011) na Bacia hidrográfica do Riacho Fundo (Felixlândia, Minas Gerais, } \\
\text { Brasil). }\end{array}$ \\
\hline $\begin{array}{l}\text { Rieger, FA; Zolin, CA; Paulino, J; } \\
\text { de Souza, AP; Matos, ED; } \\
\text { Magalhaes, CAD; Neto, ALD }\end{array}$ & 2016 & Avaliar as perdas de solo e água em diferentes sistemas integrados de produção sob chuvas naturais. \\
\hline $\begin{array}{l}\text { Rosa, MG da; Klauberg, O; Bartz, } \\
\text { MLC; Mafra, AL; de Sousa, JPFA; } \\
\text { Baretta, D }\end{array}$ & 2015 & $\begin{array}{l}\text { Relacionar os sistemas de uso da terra aos seus efeitos na distribuição dos grupos de macrofauna do solo, bem } \\
\text { como sua relação com as propriedades físicas e químicas do solo. }\end{array}$ \\
\hline $\begin{array}{l}\text { Silva, BB da; Wilcox, BP; da Silva, } \\
\text { VDR; Montenegro, SMGL; de } \\
\text { Oliveira, LMM }\end{array}$ & 2015 & $\begin{array}{l}\text { Estimar as mudanças no equilíbrio energético e evapotranspiração no Estado de São Paulo após a conversão de } \\
\text { florestas nativas do Cerrado para terras cultivadas para cana-de-açúcar e eucalipto. }\end{array}$ \\
\hline $\begin{array}{l}\text { Jesus, GL de; Silva, IR; Almeida, } \\
\text { LFJ; dos Santos, MA; Leite, FP; } \\
\text { Neves, JCL }\end{array}$ & 2015 & $\begin{array}{c}\text { Avaliar o impacto de diferentes frequências de tráfego do forwarder e o efeito de condições distintas de resíduos } \\
\text { da colheita do eucalipto ao fim da rotação subsequente na produtividade, nos atributos físicos do solo e nos } \\
\text { teores de matéria orgânica de um Latossolo Vermelho, em São João Evangelista, MG, e um Latossolo Amarelo, } \\
\text { em Belo Oriente, MG. }\end{array}$ \\
\hline $\begin{array}{l}\text { Bartz, MLC; Brown, GG; da Rosa, } \\
\text { MG; Klauberg, O; James, SW; } \\
\quad \text { Decaens, T; Baretta, D }\end{array}$ & 2014 & $\begin{array}{l}\text { Avaliar a riqueza das espécies de minhocas em cinco diferentes sistemas de uso da terra com crescente impacto } \\
\text { antropogênico: floresta nativa, plantação de eucalipto, pastagem, lavoura-pecuária integrada e plantio direto, em } \\
\text { seis municípios, sendo três das regiões Oeste e Planalto do estado. }\end{array}$ \\
\hline $\begin{array}{l}\text { Viola, MR; Mello, CR; Beskow, S; } \\
\text { Norton, LD }\end{array}$ & 2014 & $\begin{array}{c}\text { Simular, utilizando o modelo LASH, os impactos sobre o regime hidrológico no UGRB com cinco tendências de } \\
\text { uso da terra: S-1 e S-2 - reflorestamento com eucalipto cobrindo } 20 \% \text { e } 50 \% \text {, respectivamente, da área atual do } \\
\text { pasto; S-3 - reflorestamento com eucalipto cobrindo } 100 \% \text { da área atual de pastagem apenas nas sub-bacias } \\
\text { onde essa tendência é predominante; S- } 4 \text { e S-5 desmatamento de } 30 \% \text { e } 70 \% \text { dos remanescentes florestais na } \\
\text { região da Serra da Mantiqueira para o cultivo de pastagens, respectivamente. }\end{array}$ \\
\hline $\begin{array}{l}\text { Rosalino, LM; Martin, PS; Gheler- } \\
\text { Costa, C; Lopes, PC; Verdade, LM }\end{array}$ & 2014 & $\begin{array}{l}\text { Identificar uma possível influência das distâncias das demais áreas de revegetação nativa e dos sistemas } \\
\text { ribeirinhos, sobre distribuição espacial e abundância de mamíferos de pequeno porte nas plantações de eucalipto. }\end{array}$ \\
\hline $\begin{array}{l}\text { Gomide, PHO; Silva, MLN; de } \\
\text { Castro, GC; Soares, CRFS; } \\
\text { Oliveira, AH; Curi, N }\end{array}$ & 2014 & $\begin{array}{l}\text { Caracterizar a vegetação em regeneração natural e plantada em áreas de voçorocas no Sul de Minas Gerais, } \\
\text { Brasil, assim como a distribuição e ocorrência das espécies podem gerar informações para um diagnóstico } \\
\text { adequado sobre o estágio de desenvolvimento das voçorocas e para a conservação do solo. }\end{array}$ \\
\hline Gainsbury, AM; Colli, GR & 2014 & Avaliar os efeitos das plantações abandonadas de eucalipto na estrutura das comunidades de lagartos do Cerrado. \\
\hline $\begin{array}{c}\text { Menezes, CWG; Soares, MA; } \\
\text { Santos, JB; Assis, SL; Fonseca, AJ; } \\
\text { Zanuncio, JC }\end{array}$ & 2012 & $\begin{array}{l}\text { Avaliar o efeito dos herbicidas usados nas culturas de eucalipto no parasitoide Palmistichus elaeisis Delvare e } \\
\text { LaSalle, } 1993 \text { (Hymenoptera: Eulophidae) em termos do impacto na reprodução e sobrevivência. }\end{array}$ \\
\hline
\end{tabular}

Fonte: Autores.

\section{Expansão de Eucalyptus spp. no Brasil}

Eucalyptus é um dos maiores gêneros de plantas do planeta, tendo sido descrito por L'Héritier em 1789. Nativo da Austrália, Papua-Nova Guiné, Timor Leste, Indonésia e Filipinas, com ocorrência nos mais diversos tipos de ambiente, em diferentes regiões, de tropicais até temperadas, extremamente úmidas a aquelas com baixos índices pluviométricos e até mesmo em pico de montanhas nevadas. Tanta diversidade permite encontrar táxons de até 90 metros de altura e com apenas 40 centímetros, com morfologia complexa em relação ao tronco, folhas, inflorescências, frutos e sementes (Flores et al., 2016).

Não se tem registros precisos sobre a introdução de eucalipto no Brasil. De acordo com Andrade (1928), o eucalipto foi introduzido no Brasil em 1868, sendo os primeiros exemplares plantados no Rio Grande do Sul e Rio de Janeiro. Entretanto, existem relatos que em São Paulo já existiam alguns plantios de Eucalyptus globulus antes dessa data (Viana, 2004). 
Os primeiros exemplares foram usados como plantas decorativas e quebra-ventos, até que Edmundo Navarro de Andrade, após plantar diferentes espécies, percebeu que o eucalipto se destacava quanto ao crescimento rápido, boa quantidade de lenha, bom poder calorífero e boa adaptação ao ambiente brasileiro. Então, por volta do século XX teve início a produção visando a cultura econômica, sendo usados como fonte de energia para o abastecimento da maior ferrovia brasileira, a Companhia Paulista de Estradas de Ferro, sob os cuidados de Navarro, o qual é considerado o pioneiro na produção da silvicultura comercial (Hasse, 2006; Amorim et al., 2021; Rodrigues et al., 2021).

A produção de eucalipto em larga escala ganhou força a partir de 1909, quando foi sancionada a Lei $\mathrm{n}^{\mathrm{o}} 5.106$, de incentivos fiscais. Os incentivos eram recolhidos do Fundo de Investimento Setorial de Reflorestamento e aplicados mediante apresentação de projeto ao Instituto Brasileiro de Desenvolvimento Florestal (IBDF) (Lima, 1996; Viana, 2004). Buscando-se aumentar a implantação das áreas de árvores pra fins comerciais, o governo promulgou o Decreto Lei n. ${ }^{\circ}$ 1.134/1970, que estipulava o abatimento do imposto de renda com a simples aprovação do projeto de plantio pelo IBDF, antes mesmo dele ser efetivado (Brasil, 1970). Com os incentivos fiscais a área plantada de eucalipto teve significativo crescimento, passando de 470.000 para 3,2 milhões de hectares, de 1909 a 1966. Em 1987, esses incentivos foram finalizados. Entretanto, já existia tecnologia suficiente para manter o crescimento da produção de eucalipto no país (Pereira et al., 2000). O desmatamento acelerado no interior paulista, para abastecer o setor ferroviário, foi intensificado e, por volta de 1930, já era possível perceber as grandes mudanças provocadas nas paisagens causadas pelo plantio em larga escala do eucalipto (Foelkel, 2005).

Outra contribuição para a ascensão do plantio de eucalipto, segundo Lima (1996), se deve à crise energética nos anos 70, a qual deu grande impulso na demanda de madeira e, consequentemente, o aumento do interesse na utilização de eucalipto, contribuindo com a formação de plantações florestais em larga escala. Assim, foi instituído o II Plano Nacional de Desenvolvimento (IIPND), entre 1975 e 1979, do qual fazia parte o Programa Nacional de Papel e Celulose (PNPC), o Plano Siderúrgico a Carvão Vegetal e o Programa de Substituição Energética, os quais apresentavam outros estímulos para a expansão das indústrias siderúrgica, de papel e celulose, e consequentemente, para o plantio de eucalipto e de pinus (Antonangelo \& Bacha, 1998; Bacha, 2008). Além disso, numa tentativa de realizar a implantação de áreas de silvicultura de forma racional e planejada, ocorreu a criação dos "Distritos Florestais", em 1975, em parceria com o Programa das Nações Unidas para o Desenvolvimento (PNUD), a Organização de Alimentação e Agricultura das Nações Unidas (FAO) e o IBDF; e a elaboração do "Zoneamento Ecológico Esquemático para Reflorestamento no Brasil”, em 1978 (Rodrigues et al., 2021).

Nesse período a indústria nacional de celulose se aproximou dos grandes grupos do setor (norte-americanos, japoneses e escandinavos), sendo uma das principais causas o aspecto altamente poluidor da fabricação da pasta de celulose. Na fabricação de papel são usados, de forma intensa, produtos químicos poluentes como enxofre, cloro e soda cáustica, o quais foram proibidos a partir dos anos de 1970 nos países escandinavos. Como o produto final da indústria de celulose possui baixo valor agregado, tornou-se mais promissor o investimento em outras regiões do mundo, onde as preocupações com a conservação ambiental eram incipientes, como no caso do Brasil, do que se investir em onerosos sistemas antipoluentes. Além disso, no Brasil havia mão-de-obra abundante, terras disponíveis para o plantio de pinus e eucalipto e incentivos fiscais governamentais (Montebello \& Bacha, 2013). Adiciona-se a esses fatores também a acelerada produtividade tanto do eucalipto como do pinus, as quais se adaptaram bem às condições climáticas no Brasil, de cerca de 7 e 25 anos respectivamente, em comparação com a de outros países, como por exemplo na Escandinávia, onde para o crescimento, o eucalipto leva cerca de 30 anos e o pinus, 70 anos (Foelkel, 2005).

Dessa forma, o incremento do uso do eucalipto nos setores siderúrgico, de papel e celulose, propiciou uma nova fase de territorialização do eucalipto, na qual os incentivos fiscais governamentais tiveram papel decisivo para a consolidação da eucaliptoculura em São Paulo e para a sua expansão para Minas Gerais, Bahia, Espírito Santo e Mato Grosso do Sul (Rodrigues et al., 2021). A década de 1980, considerada como perdida na economia brasileira, para a indústria de celulose foi 
de expansão e modernização. Os incentivos fiscais tanto para a indústria siderúrgica, como para o setor de celulose e para o plantio de árvores comerciais, entre 1970 e 1986, resultou em modernização tanto no setor industrial quanto na pesquisa voltada para o plantio, colheita e processamento do eucalipto (Medeiros et al., 2020; Rodrigues et al., 2021).

Já nos anos de 1990 ocorreu o término dos incentivos fiscais e isso culminou em um crescimento marginal negativo no plantio de eucalipto. Além disso, a redução do consumo de carvão devido à recessão e ao preço do coque, também provocou a redução da área de árvores pra fins comerciais voltada para o setor siderúrgico, na primeira metade da década de 1990 (Rodrigues et al., 2021). Entretanto, o setor independente dos investimentos, como o das indústrias de papel e celulose e siderúrgicas a carvão vegetal moderado, manteve esse plantio de árvores. As reformas do Plano Real, no governo de Fernando Henrique Cardoso, atraíram investimentos diretos estrangeiros para o setor. As indústrias ampliaram a capacidade instalada, a celulose passou a ser exportada para os países setentrionais e o setor do plantio de árvores passou a inserir-se cada vez mais no cenário comercial internacional (Montebello et al., 2013). Neste viés, a demanda do mercado externo nas duas últimas décadas posicionou o Brasil em patamares elevados no contexto mundial de produção de celulose e fez com que houvesse um incremento nas áreas de eucalipto voltadas para esse setor (Afonso et al., 2021; Rodrigues et al., 2021). Além disso, existe também a demanda do mercado interno, sendo os fatores condicionantes da produção de lenha: a demanda por secagem de grãos no setor agrícola das regiões Centro-Oeste e Sul, principalmente devido à expansão da soja; o setor de cerâmica no Nordeste; e outros setores industriais distribuídos em todo o Brasil. Assim, entre 1998 e 2017, a produção de lenha em microrregiões especializadas em lenha do extrativismo foram fortemente substituídas pelos de base na silvicultura nas regiões Sul, Sudeste e Centro-Oeste para atender a demanda dos processos agroindustriais (Bichel \& Telles, 2021). Isso resultou em uma grande expansão da área plantada de eucalipto no Brasil e, na última década, essa monocultura aumentou de 4,9 milhões de ha em 2010 para 7,5 milhões de ha em 2020 (Quadro 2) (IBÁ, 2021).

Os Estados de Minas Gerais (27,6\%), São Paulo (18,1\%), Mato Grosso do Sul (15,1\%), Bahia (7,8\%), Rio Grande do Sul (6,6\%), Paraná e Santa Catarina (3,6\% cada) seguem como principais produtores de áreas plantadas com árvores pra fins comerciais no país (Figuras 2 e 3; Quadro 2). Considerando os três estados com maior concentração de eucalipto, em Minas Gerais, a maior parte da produção é destinada para a produção de carvão vegetal, e em Mato Grosso do Sul e São Paulo, para papel e celulose (Rodrigues et al., 2021). Nos últimos anos as áreas de eucalipto da Bahia e Espírito Santo tiveram o ritmo de expansão estabilizado; São Paulo e Minas Gerais continuam a se manter como os estados onde ocorre a maior área de eucalipto plantado e iniciou-se a emergência de novos espaços de eucaliptocultura no sul do Brasil nos estados de Mato Grosso do Sul, Rio Grande do Sul (veja em Chaves et al., 2021), Paraná e Santa Catarina. Atualmente, o Sul do Brasil tem a maior produção de lenha baseada na silvicultura, seguido pelo Sudeste (Bichel et al., 2021). 
Quadro 2. Expansão da área plantada por eucalipto (em hectares) por estados (em ordem decrescente quanto à área cultivada por esta monocultura) e no Brasil de 2010 a 2020.

\begin{tabular}{|c|c|c|c|c|c|c|c|c|c|c|c|}
\hline Estado & 2010 & 2011 & 2012 & 2013 & 2014 & 2015 & 2016 & 2017 & 2018 & 2019 & 2020 \\
\hline $\mathrm{MG}$ & 1.400 .000 & 1.401 .787 & 1.438 .971 & 1.404 .429 & 1.400 .232 & 1.395 .032 & 1.390 .032 & 1.381 .652 & 1.977 .410 & 2.231 .754 & 2.060 .260 \\
\hline SP & 1.044 .813 & 1.031 .677 & 1.041 .695 & 1.010 .444 & 976.186 & 976.613 & 946.124 & 937.138 & 1.040 .284 & 1.417 .708 & 1.354 .734 \\
\hline MS & 378.195 & 475.528 & 587.310 & 699.128 & 803.699 & 826.031 & 877.795 & 901.734 & 1.093 .805 & 1.111 .737 & 1.124 .637 \\
\hline BA & 631.464 & 607.440 & 605.464 & 623.971 & 630.808 & 614.390 & 612.199 & 608.781 & 585.269 & 589.336 & 585.600 \\
\hline $\mathrm{RS}$ & 273.042 & 280.198 & 284.701 & 316.446 & 309.125 & 308.515 & 308.178 & 309.602 & 426.371 & 456.001 & 491.076 \\
\hline $\mathrm{SC}$ & 102.399 & 104.686 & 106.588 & 107.345 & 112.944 & 116.250 & 116.240 & 114.513 & 219.199 & 255.682 & 273.116 \\
\hline PR & 161.422 & 188.153 & 197.835 & 200.473 & 224.089 & 285.125 & 294.050 & 295.520 & 255.955 & 271.042 & 271.042 \\
\hline ES & 203.885 & 197.512 & 203.349 & 221.559 & 228.781 & 227.222 & 233.760 & 234.082 & 225.520 & 225.311 & 230.918 \\
\hline MA & 151.403 & 165.717 & 173.324 & 209.249 & 211.334 & 210.496 & 221.859 & 228.801 & 200.612 & 199.911 & 224.676 \\
\hline MT & 150.646 & 175.592 & 184.628 & 187.090 & 187.090 & 185.219 & 185.219 & 181.515 & 187.947 & 188.838 & 180.625 \\
\hline GO & 116.439 & 118.636 & 115.567 & 121.375 & 124.297 & 127.201 & 127.201 & 127.201 & 127.201 & 159.943 & 159.943 \\
\hline PA & 148.656 & 151.378 & 159.657 & 159.657 & 125.110 & 130.431 & 133.996 & 135.843 & 151.888 & 154.402 & 155.941 \\
\hline TO & 47.542 & 65.502 & 109.000 & 111.131 & 115.564 & 116.365 & 116.798 & 118.443 & 149.988 & 149.291 & 148.892 \\
\hline $\mathrm{AP}$ & 49.369 & 50.099 & 49.506 & 57.169 & 60.025 & 63.026 & 65.026 & 67.826 & 67.826 & 67.826 & 67.826 \\
\hline Outros & 41.675 & 35.807 & 46.568 & 43.710 & 49.369 & 48.691 & 45.307 & 44.558 & 74.905 & 146.403 & 143.035 \\
\hline Brasil & 4.900 .950 & 5.049 .712 & 5.304 .163 & 5.473 .176 & 5.558 .653 & 5.630 .607 & 5.673 .784 & 5.687 .209 & 6.784 .179 & 7.625 .186 & 7.472 .321 \\
\hline
\end{tabular}

Fonte: IBÁ (2021).

Figura 2. Área plantada com eucalipto em milhões de hectares, em 2020, por estado no Brasil.

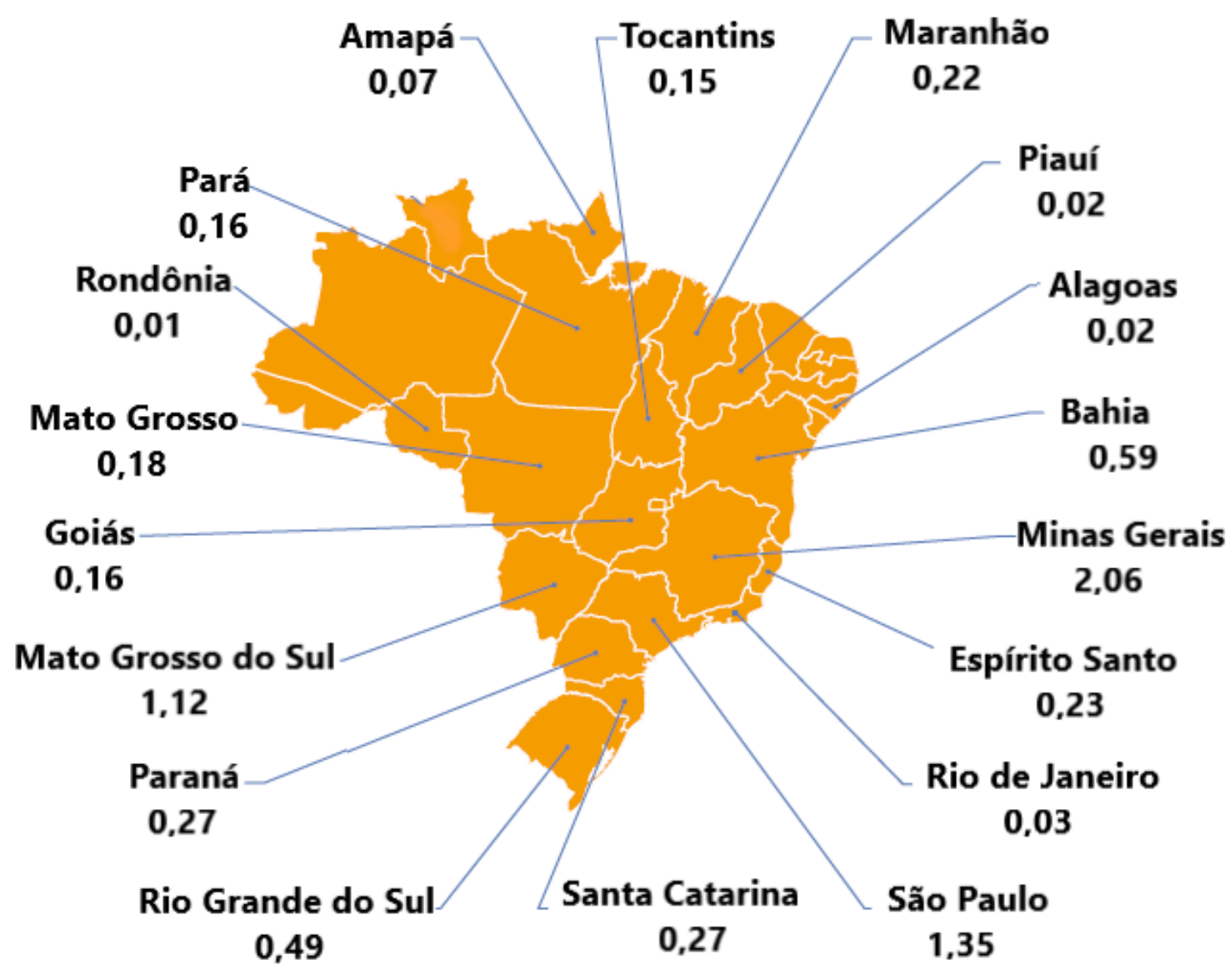

Fonte: adaptado de IBÁ (2021). 
Nesses estados da região sul, tradicionalmente a exploração madeireira foi subsidiada pelo corte de araucárias e de outras espécies nativas de menor expressão. Entretanto, a escassez da madeira nativa e os incentivos fiscais impulsionaram o plantio de árvores comerciais, com o objetivo de substituir a araucária, como matéria-prima, na indústria moveleira e de celulose e papel. Neste contexto, no início dos anos 2000 os estados da região sul tiveram notável incremento na instalação de grandes empresas do setor de árvores plantadas pra fins comerciais, as quais investiram no plantio de eucaliptos aliado às novas tecnologias (como a impregnação de papel melamínico que confere a cor desejada às placas de eucalipto) e com experimentos genéticos (tornaram a madeira de eucalipto mais flexível e com maior qualidade), viabilizando, dessa forma, o uso da madeira de eucalipto também na indústria moveleira. Outra explicação para a expansão da eucaliptocultura foi a opção de muitas empresas do setor de árvores plantadas investirem no cultivo de eucalipto, haja vista que o eucalipto é uma espécie versátil e atinge a maturidade em torno de 7 anos (o pinus necessita de 14 a 15 anos para estar apto para a comercialização), e é muito adaptável às condições climáticas tropicais úmidas e semiúmidas dominantes no país e às subtropicais úmidas do sul, abrangendo os estados do Paraná, Santa Catarina e Rio Grande do Sul (Rodrigues et al., 2021). Eucalyptus grandis, Eucalyptus saligna, Eucalyptus urophylla, Eucalyptus viminalis, híbridos de E. grandis x E. urophylla e Eucalyptus dunniias são as espécies mais cultivadas no Brasil (Embrapa, 2019).

Figura 3. A) Percentual da área com plantio de eucalipto por estado em comparação com a área total de eucaliptocultura no Brasil, em 2020, e B) evolução da área com plantios de eucalipto por estado entre 2014 e 2020.

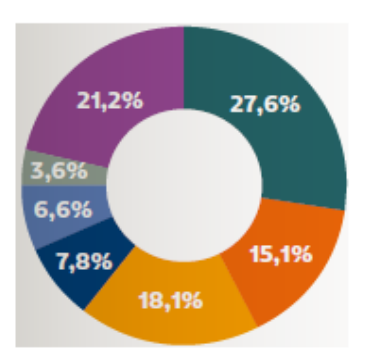

A
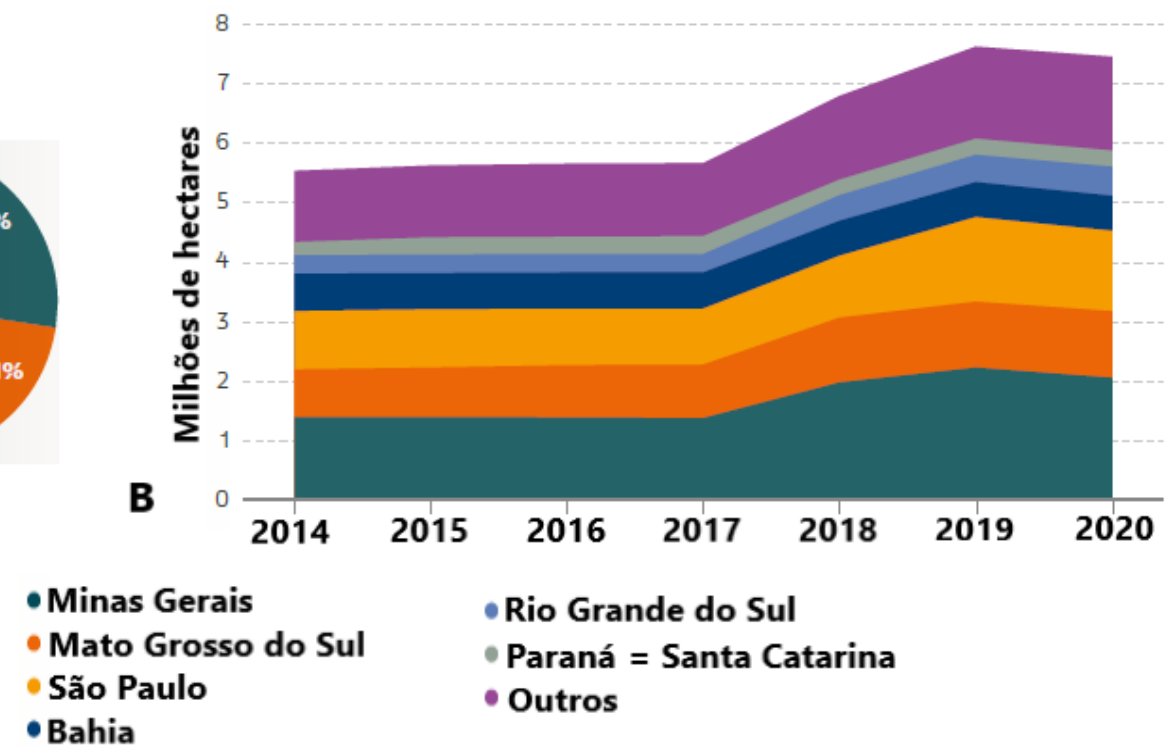

Fonte: adaptado de IBÁ (2021).

Entre esses estados o Mato Grosso do Sul foi o que apresentou maior crescimento na área de plantio de eucalipto, de 378.195 ha, em 2010, para 1.124.637 ha, em 2020 (IBÁ, 2021), e essa expansão se deve à ampliação do setor a partir da atuação principalmente das empresas do complexo eucalipto-celulose-papel, como a Suzano Papel e Celulose e Eldorado Brasil. Estas empresas encontraram no Mato Grosso do Sul condições favoráveis para promover a expansão da área de eucaliptocultura, tais como: condições de ordem natural, como clima, relevo, hidrografia e solos adequados para florestas plantadas extensas; áreas improdutivas com origem na apropriação privada da terra; disponibilidade e baixo valor da terra; isenções fiscais concedidas pelo Estado e a pouca (ou nenhuma) atuação de movimentos sociais de luta pela terra (Baratelli et al., 2020). Assim, na última década, no Mato Grosso do Sul estabeleceu-se o intenso processo de territorialização do capital monopolista no campo, por meio da (agro)industrialização, em especial a eucaliptocultura, com elementos favoráveis para sua 
implantação e permanência, tais como a concentração fundiária e a atuação do Estado na dotação de infraestrutura e nos incentivos fiscais (Baratelli et al., 2020).

Entre 2017 e 2019 houve um acelerado crescimento na área de plantio de eucalipto nos estados de Minas Gerais, São Paulo, Mato Grosso do Sul, Rio Grande do Sul, Santa Catarina e Paraná, mas, por outro lado, as mudanças climáticas podem ter sido um dos fatores que culminaram na queda de produtividade média por ano no plantio de eucalipto de $38,6 \mathrm{~m} 3 / \mathrm{ha}^{2}$, em 2019, para 36,8 m³/ha, em 2020 (Figura 3B; Quadro 2) (IBÁ, 2021).

Embora a expansão da eucaliptocultura tenha avançado entre os principais estados produtores do setor, a proporção da área ocupada por esta monocultura em comparação com a área territorial desses estados ainda pode ser considerada baixa, sendo os estados de São Paulo (5,5\%) e Espírito Santo (5\%) os que apresentam maior ocupação da monocultura (Tabela 1). Entretanto, é válido ressaltar que a distribuição da eucaliptocultura nos estados não acontece de maneira homogênea e tende a se concentrar em algumas regiões desses estados (ver Baratelli et al., 2020). As empresas que desenvolvem atividades neste setor tendem a se instalar em territórios com melhores condições de infraestrutura logística, de geração de energia e com abundância de recursos hídricos, conjunto de fatores que favorece a geração de economia de escala e, por consequência, a competitividade no cultivo e na indústria desta monocultura (Moledo et al., 2016).

Tabela 1. Comparação entre a área dos principais estados brasileiros produtores de eucalipto e a área ocupada por esta monocultura em 2020.

\begin{tabular}{|c|c|c|c|}
\hline Estados & $\begin{array}{l}\text { Área do estado } \\
\text { (ha) }\end{array}$ & $\begin{array}{l}\text { Área da eucaliptocultura } \\
\text { em } 2020 \text { (ha) (IBÁ, 2021) }\end{array}$ & $\begin{array}{l}\text { \% da área ocupada pela } \\
\text { eucaliptocultura no estado }\end{array}$ \\
\hline Minas Gerais & 58.652 .800 & 2.060 .260 & 3,5 \\
\hline São Paulo & 24.820 .900 & 1.354 .734 & 5,5 \\
\hline Mato Grosso do Sul & 35.712 .500 & 1.124 .637 & 3,1 \\
\hline Bahia & 56.729 .500 & 585.600 & 1,0 \\
\hline Rio Grande do Sul & 28.174 .800 & 491.076 & 1,7 \\
\hline Santa Catarina & 9.534 .600 & 273.116 & 2,9 \\
\hline Paraná & 19.931 .500 & 271.042 & 1,4 \\
\hline Espírito Santo & 4.609 .500 & 230.918 & 5,0 \\
\hline Maranhão & 33.198 .300 & 224.676 & 0,7 \\
\hline Mato Grosso & 90.335 .700 & 180.625 & 0,2 \\
\hline Goiás & 34.008 .600 & 159.943 & 0,5 \\
\hline Pará & 124.800 .000 & 155.941 & 0,1 \\
\hline Tocantins & 27.762 .100 & 148.892 & 0,5 \\
\hline Amapá & 14.281 .500 & 67.826 & 0,5 \\
\hline
\end{tabular}

Fonte: Autores.

Para Ross (2021) a eucaliptocultura no Brasil é preferencialmente cultivada em condições de relevo e ou de solos menos aptos para agricultura mecanizada de grãos, café, cana-de-açúcar e citros, cultivos que exigem relevos pouco declivosos e ou solos mais férteis. Estes cultivos ocupam extensas áreas de planaltos e chapadas com solos profundos e bem desenvolvidos, extremamente valorizados cujos preços por hectare são incompatíveis para a prática da silvicultura em face da relação custo da terra frente aos benefícios esperados com o tempo mais longo para retorno do investimento. Deste modo, as terras de custos mais compatíveis com a silvicultura encontram-se nas áreas onde as condições de relevo são mais declivosas, como morros e serras, com solos menos aptos para a agricultura de alimentos em sistema mecanizado de produção ou mesmo de pecuária de cria e corte. Logo, urge a necessidade da realização de pesquisas que considerem o panorama da distribuição da eucaliptocultura para cada um dos estados brasileiros de grande produção de eucalipto, associada às condições edafoclimáticas, sociais e políticas que subsidiem uma análise mais complexa e abrangente acerca dos impactos desta monocultura em cada um desses estados. Vale destacar aqui a recente e ampla contribuição nesse sentido realizada por Rezende et al. (2013); Afonso e Miller (2021); Rodrigues et al. (2021) e Teixeira e Rodrigues (2021) para Minas Gerais.

$\mathrm{Na}$ vanguarda de um crescimento verde, a tendência de áreas com árvores cultivadas pra fins comerciais continua forte (Souza et al., 2021), principalmente em decorrência da mudança de hábitos dos consumidores, mercados e investidores 
em busca de produtos sustentáveis, diante da realidade das mudanças climáticas. Durante os aproximadamente 200 anos da presença do eucalipto em terras brasileiras, o seu uso econômico se diversificou. Primeiramente, extremamente atrelado ao uso energético, como lenha de locomotivas e de indústrias, sobretudo siderúrgicas, e, no presente momento, constitui relevante importância no setor de papel e celulose e de processamento de toras em compensados, lâminas e chapas (Rodrigues et al., 2021). O Brasil está entre os maiores produtores de eucalipto do mundo, tendo sido o maior exportador de celulose no mercado mundial em 2020 (Figura 4). No setor de árvores plantadas pra fins comerciais, a celulose representa $61 \%$ dos produtos exportados e os principais destinos de sua exportação, em 2020, foram China e Estados Unidos com 48\% e 16\%, respectivamente (IBÁ, 2021).

Figura 4. Principais países exportadores de celulose (US\$ Bilhões).

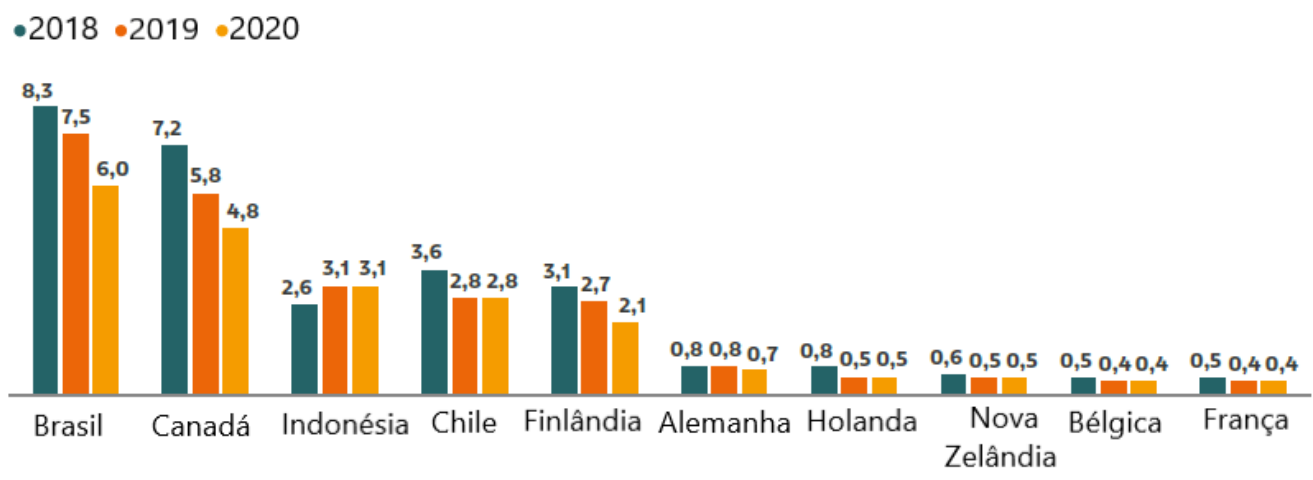

Fonte: Adaptado de IBÁ (2021).

Apesar da pandemia, a produção de celulose no Brasil continuou crescendo em 2020, com um aumento de 6,4\% de 2019 para 2020 (Figura 5A). O país se manteve como segundo maior produtor mundial, atingindo 21 milhões de toneladas (Figura 5B), das quais $75 \%$ foi destinada para exportação, totalizando 15,6 milhões de toneladas. O mercado doméstico foi responsável pelo consumo de 5,3 milhões de toneladas (IBÁ, 2021).

Figura 5. A) Produção brasileira de celulose e B) principais produtores mundiais de celulose.

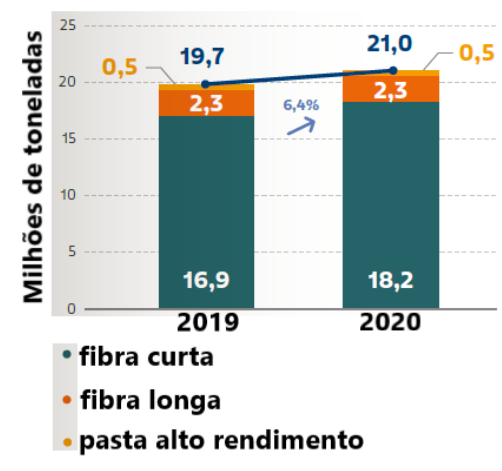

A

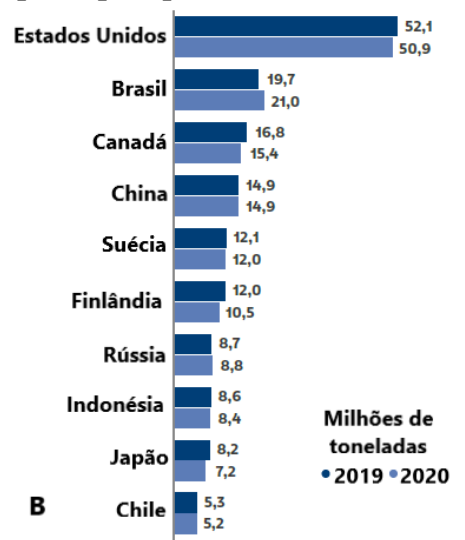

Fonte: adaptado de IBÁ (2021).

\section{Impactos benéficos oriundos da produção de Eucalyptus}

Com a expansão da produção de Eucalyptus, o gênero se tornou tema de debates entre ambientalistas e os que se dedicam à sua produção. As opiniões se dividem consoante aos interesses e ao nível de conhecimento a respeito do tema. “Alguns consideram o eucalipto o "ouro verde do campo", enquanto outros o acusam de produzir um "deserto verde”, ou o chamam de "o grande vilão do meio ambiente" (Scolforo, 2008). Mas, indubitavelmente, todas as atividades das fases de 
implantação, manutenção e colheita da eucaliptocultura, resultam em modificações das condições socioambientais outrora existente no local (Rodrigues et al., 2021; Ebling et al., 2021).

Entre os pontos positivos da produção de eucalipto em larga escala está a contribuição positiva à economia nacional, pois, gera um incremento comercial, com produtos de consumo interno e para exportação, impostos e empregos para a população (Vital, 2007; IBÁ, 2021). É inquestionável que o cultivo de florestas plantadas (aqui incluídas as espécies de eucalipto, pinus, teca e outras) é uma necessidade crescente no Brasil em função das diversas demandas internas e externas de madeira como matéria prima para construção civil, móveis, papel e celulose (Bichel et al., 2021). Essa matéria prima também é usada como fonte de energia a lenha para as indústrias cerâmicas, alimentícia, agroindústria e secadores de grãos como soja, milho, arroz, café entre outros. Como exemplo, grande parte da demanda de energia para as agroindústrias de abate de aves e suínos é suprida pela biomassa de eucalipto na forma de cavacos de madeira (Lenz et al., 2019). A integração bioenergiapecuária consiste numa estratégia de benefícios mútuos para a mitigação do clima e para suprir as demandas de alimentos e fibras da sociedade, usando subprodutos da bioenergia como ração animal para liberar terras para a produção de culturas industriais adicionais (Fiorese, 2021; Souza et al., 2021; Zolin et al., 2021). Mas, a fonte de energia de maior destaque está na utilização do eucalipto para a produção de carvão vegetal utilizado nas indústrias siderúrgicas (Rodrigues et al., 2021). Vale dizer aqui, que há uma estimativa de que, até 2050, a bioenergia irá suprir 30\% da demanda de energia do mundo (Guo et al., 2015).

Produz-se, ainda, das árvores cultivadas, desinfetantes, aromatizantes, espessantes, solventes, vernizes, colas, borracha sintética, tintas para impressão, ceras e graxas, papeis para impressão, higiênicos, sanitários, fraldas, embalagens, móveis, palets, caixotarias, viscose etc. Além disso, a partir da adoção de nanotecnologia, a celulose que apresenta propriedades como resistência, impermeabilidade e condutividade, torna-se uma alternativa sustentável a itens de diversos segmentos como tecidos, curativos, álcool em gel, tinta e concreto. Já a lignina, a partir de muita pesquisa aplicada tem enorme potencial de substituir fenol e poliuretano em resinas ou ser utilizado na produção de bio-óleos. Essas matérias primas de componentes de base renovável podem ser usadas na confecção de telas de telefone, peças de avião, filmes de alta resistência mecânica que podem ser aplicados em telas de televisores, filmes curativos, painéis fotovoltaicos orgânicos bioplásticos, biocombustíveis, entre outros (IBÁ, 2021).

Os produtos das áreas de árvores plantadas pra fins comerciais contribuíram com a balança comercial gerando uma receita bruta estimada do setor, em 2020, de R\$-116,6 bilhões, um crescimento de 17,6\% em relação a 2019. Em 2020 a produção de celulose alcançou seu segundo maior volume histórico, totalizando 21 milhões de toneladas. Enquanto o PIB do país cresceu apenas $2,7 \%$ de 2010 a 2020, o valor adicionado da cadeia produtiva do setor de árvores cultivadas pra fins industriais no PIB apresentou incremento de 10,2\%, no mesmo período. O desempenho superior deste setor ocorreu mais especificamente a partir de 2016. Este é um setor que desde a década de 80 tem investido para atuar junto das cadeias globais, uma decisão estratégica, contribuindo cada vez mais para a balança comercial do país. Neste cenário, nota-se expressiva redução da participação dos produtos característicos da cadeia produtiva da indústria brasileira de árvores pra fins comerciais na pauta de importações. Em 2010 estes produtos representavam 1,2\% do total das importações do país, em 2020 este percentual foi de $0,6 \%$ (IBÁ, 2021).

De um total de 50 atividades representativas de toda a economia brasileira, a cadeia produtiva de árvores cultivadas pra fins industriais aparece na $22^{\mathrm{a}}$ posição como a atividade de maior contribuição para o produto interno bruto brasileiro, com dados estimados para a média do período de 2010 a 2020. Se forem consideradas apenas as atividades do setor industrial, a posição da cadeia produtiva de árvores plantadas pra fins industriais sobe para a $5^{\mathrm{a}}$ colocação no ranking, ficando atrás apenas das atividades de construção civil ( $1^{\mathrm{a}}$ posição), eletricidade, gás, água, esgoto e limpeza urbana ( $\left.2^{\mathrm{a}}\right)$, alimentos e bebidas $\left(3^{\mathrm{a}}\right)$ e máquinas e equipamentos $\left(4^{\mathrm{a}}\right)$. Paralelo a isso, tem a geração de renda e emprego, a qual cresce ao longo da cadeia produtiva. 
As atividades do setor de floresta cultivada contribuíram para a geração de mais de 536 mil empregos diretos e 1,5 milhão de postos de trabalho indiretos (IBÁ, 2021). Em estudo realizado por Afonso e Miller (2021), para todos os municípios mineiros com produção de eucalipto, os resultados evidenciam que o aumento da área de plantio florestal está associado a uma diminuição da pobreza ao longo do tempo.

Além das contribuições com a balança comercial do país, a silvicultura também colabora com o meio ambiente (Bertola, 2013). A partir de acordos como do Protocolo de Kyoto que propõe a redução da emissão de gases como o $\mathrm{CO}_{2}$, surgiu a criação de um mercado para crédito de carbono a partir das áreas plantadas com árvores pra fins comerciais. Os projetos florestais que incluem florestamentos e reflorestamentos com árvores pra fins comerciais ganham espaço, uma vez que as árvores promovem a fixação de carbono de forma bastante eficiente, durante seu desenvolvimento (Juvenal \& Matos, 2002; Medeiros et al., 2020; Bichel \& Telles, 2021; IBÁ, 2021). As plantações de eucalipto contribuem com a fixação de carbono especialmente se elas estiverem inseridas em um sistema agrossilvipastoril, o qual consiste no cultivo integrado de eucalipto com espécies agrícolas e pastagem para a criação de bovinos, de forma escalonada no tempo (Tsukamoto Filho et al., 2004; Lenz et al., 2019). O sistema agrossilvipastoril possibilita benefícios ecológicos, ambientais e econômicos e consiste em um importante recurso no combate à pobreza na zona rural e propicia segurança alimentar e conservação dos recursos naturais (Fiorese, 2021).

Neste viés, o setor brasileiro de árvores plantadas pra fins comerciais pode contribuir para dirimir os impactos das mudanças climáticas, que é um dos principais problemas ambientais da atualidade, desde que o setor seja subsidiado por quatro pilares: carbono estocado em florestas naturais e de produção; carbono removido em florestas naturais e de áreas de produção de árvores pra fins comerciais; emissões evitadas provenientes das indústrias e uso de energia renovável; e estoque de carbono em produtos de origem florestal (Medeiros et al., 2020; Bichel \& Telles, 2021; IBÁ, 2021; Ferreto et al., 2021). A implantação de plantios comerciais em áreas degradadas e inaptas à agricultura pode ser uma medida de mitigação das mudanças climáticas, diminuindo a poluição e o calor, por contribuir com a redução da emissão dos gases metano (gás de efeito estufa importante proveniente da atividade microbiana) e dióxido de carbono da atmosfera com a substituição de aço e concreto por madeira (Fritzsons et al., 2006).

Outro aspecto enfatizado pelos defensores das áreas plantadas de eucalipto está subsidiado pela preservação de vegetação nativa para a obtenção de produtos de base madeireira (Scolforo, 2008; Medeiros et al., 2020; Amorim et al., 2021; Bichel et al., 2021). Segundo o relatório anual da IBÁ de 2021 as áreas de árvores plantadas pra fins comerciais reduzem a pressão sobre as floretas naturais, promovendo a conservação da biodiversidade, controle hídrico, polinização, controle do clima, conservação do solo, ciclagem de nutrientes e mitigação dos efeitos das mudanças climáticas, mediante estoque de carbono nas árvores. O setor de árvores cultivadas brasileiro é referência mundial no sistema de plantio em mosaico. Em escala de paisagem, essa técnica se baseia na forma de mandala, que intercala áreas de plantio com áreas de vegetação nativa, destinada para conservação. Isso significa mais equilíbrio no uso dos recursos naturais, refúgio e corredor ecológico para os animais e flora, além de auxiliar na regulação do fluxo hídrico e demonstra que sempre haverá áreas de plantação em diferentes estágios, em pequenas mudas e até no momento da colheita ou em crescimento, para regular fluxo hídrico e para não haver grande impacto na paisagem quando colher. Enquanto as áreas de conservação formam corredores ecológicos para a biodiversidade. Quanto mais diversificado esse mosaico for, mais sustentável é o território. Esse conjunto de conhecimento e técnicas já é aplicado há anos pelo setor e ganha cada vez mais proeminência dialogando com os anseios atuais (IBÁ, 2021).

Através de um estudo com 10 eventos com maiores intensidades de precipitação para o período avaliado e através de coletas de amostras dos solos constatou-se que na área cultivada com eucalipto, havia uma menor tendência à desagregação/erosão (Costa et al., 2016). Assim, para Amorim et al. (2021) o plantio de eucalipto protege o solo contra erosões hídricas, haja vista que enquanto os indivíduos de eucalipto não foram cortados para a finalidade comercial, eles protegem o 
solo contra os impactos da gota da chuva, evitando dessa forma uma erosão. Entretanto, vale ressaltar que essa proteção do solo, aqui mencionada, é temporária e dura até o corte dos indivíduos de eucalipto para a finalidade comercial.

Diante do exposto neste tópico, o eucalipto plantado em áreas já degradadas pode contribuir para a recuperação das mesmas e reduzir o desmatamento das áreas nativas. Essa monocultura, manejada adequadamente, em sua concepção e implementação, pode contribuir para o desenvolvimento sustentável, propiciando um equilíbrio entre crescimento econômico sustentado, melhor distribuição da renda e da riqueza e qualidade adequada do meio ambiente (Rezende et al., 2013), desde que respeitadas as diretrizes do equilíbrio ecológico.

\section{Impactos adversos oriundos da produção de Eucalyptus}

Os impactos adversos causados pela produção de eucalipto em larga escala vão além de uma transformação visual, pois implica em mudanças socioambientais (Tucci et al., 1997; Larrañaga et al., 2009; Farinaci et al., 2013; Vechi et al., 2018; Baratelli et al., 2020; Rodrigues et al., 2021). À medida que a vegetação nativa e os solos agrícolas são ocupados pela eucaliptocultura, pautado pelo modelo agroexportador baseado no latifúndio monocultor, ocorrem o empobrecimento da biodiversidade local (Zanzini et al., 2017; Rosa et al., 2018; Jacoboski et al., 2019), degradação ambiental e conflitos no meio rural e urbano, culminando no sufocamento da biosociodiversidade local (Santos \& Trevisan, 2009; Sell \& Figueiró, 2011; Rezende et al., 2013; Baratelli et al., 2020; Medeiros et al., 2020; Gualberto et al., 2021).

Os prejuízos têm início desde o processo de plantio perdurando até a colheita devido à utilização de maquinário pesado, o que compromete a qualidade física do solo (vale destacar aqui a contaminação do solo por óleos combustíveis e lubrificantes das máquinas de corte e extração) e promove a compactação (veja Tassinari et al., 2019), interferindo na infiltração da água destinada aos lençóis freáticos. Esses problemas se estendem até a rotação seguinte (Cândido et al., 2014; Jesus et al., 2015; Moledo et al., 2016; Vechi \& Magalhães Júnior, 2018). Em estudo realizado por Leite (2002) o cultivo de eucalipto resultou em alterações nas características químicas do solo, aumentando a acidez potencial e diminuindo os teores de matéria orgânica e a concentração de nutrientes $(\mathrm{K}, \mathrm{Ca}$ e $\mathrm{Mg}$ ) quando comparados ao mesmo solo com pastagem e floresta nativas. Gama-Rodrigues e Gama-Rodrigues (2008) observaram que, após 10 anos de cultivo com eucalipto, houve diminuição nos índices microbiológicos em relação à floresta nativa no mesmo solo, além de apresentar uma menor relação C/N quando em comparação com a vegetação natural. A cobertura vegetal nativa, por meio das raízes e da serapilheira, fornece nutrientes para a biota do solo. A interação plantas e demais seres vivos no ambiente resulta na construção da estrutura física do solo, cuja complexidade é maior quanto maior a quantidade, qualidade, diversidade e frequência do aporte da serapilheira (Vezani \& Mielniczuk, 2009).

A conversão da área nativa para a eucaliptocultura resulta em um efeito direto na qualidade físico-hídrica do solo, devido à redução da diversidade do material orgânico aportado no solo (Chaves et al., 2021). Alterações na composição de espécies arbóreas nativas, por meio do cultivo de uma única espécie, afetam o equilíbrio das comunidades edáficas, pois reduzem o número de nichos ecológicos, favorecendo a competição intra e interespecífica, além de contribuírem para as mudanças nos fatores abióticos como temperatura, umidade, incidência de luz e as condições físico-químicas do solo (Gualberto et al., 2021). Após 10 anos de área de cerrado ter sido convertida em eucaliptocultura foi verificado um aumento na densidade do solo, o que reduziu a dinâmica hídrica e atmosférica do solo em relação à vegetação nativa (Cavenage et al., 1999). Além disso, o intenso tráfego de maquinários em áreas de eucalipto, para o corte e transporte da madeira, resulta no aumento da densidade e redução da porosidade do solo devido à compactação, interferindo, de forma negativa, na dinâmica da água e circulação de ar no perfil do solo (Silva et al., 2007, Reichert et al., 2007; Tassinari et al., 2019). Assim, entre as medidas para mitigar os impactos negativos no solo, resultante da eucaliptocultura, estão: a realização de subsolagem do terreno no sentido perpendicular ao de maior declividade ou em nível; a adoção de técnicas mecânicas, edáficas e vegetativas 
de conservação do solo; manter restos da exploração do eucalipto no solo; o uso de equipamentos pneumáticos com maior área de contato no solo para máquinas pesadas; o descarte, segregação e destinação correta de resíduos sólidos de acordo com as normas vigentes (Rodrigues et al., 2021); a adoção de estratégias de manejo visando evitar a compactação do solo considerando o modelo de capacidade de carga do solo (Tassinari et al., 2019) e realizar a manutenção do maquinário e veículos em local próprio, com sistema de tratamento de efluentes, de forma a evitar a contaminação do solo.

A introdução de uma plantação de eucalipto em áreas de vegetação natural ou próximo a elas ocasiona alterações na fauna e na flora, principalmente quanto à diminuição da diversidade (Zanzini et al., 2017; Rosa et al., 2018 e Jacoboski et al., 2019). Essas alterações são causadas pela sombra, competição por recursos, alelopatia, perturbações no solo (Poore \& Fries, 1985; Farinaci et al., 2013; Moledo et al., 2016); estresse e afugentamento da fauna silvestre devido aos ruídos (ocasionados pelo trânsito de caminhões, máquinas e pessoas) e devido à redução de habitat e diminuição de oferta de recursos naturais (principalmente alimentares para a fauna) - o que, consequentemente, reduz o número de predadores e aumenta o índice de pragas (Rosa et al., 2018; Vechi \& Magalhães Júnior, 2018; Gualberto et al., 2021; Rodrigues et al., 2021) ao substituir ou reduzir a diversidade vegetal outrora existente no local pelo eucalipto. As perturbações fazem com que muitos animais deixem a vegetação nativa, acuados, e acabem invadindo as propriedades da região. Com isso, várias empresas mantém o discurso de que estão registrando várias espécies da fauna, inclusive ameaçadas de extinção, nas áreas de plantio com árvores pra fins comerciais e auxiliando, dessa forma, na sua proteção e conservação (veja em IBÁ, 2021). Entretanto, tais espécies não eram vistas tão comumente pela região, pois estavam abrigadas em seu habitat natural, não necessitando buscar alimento ou refúgio em áreas antropizadas (Sell et al., 2011).

No estudo de Jacoboski et al. (2019) no sul do Brasil, onde predominam os campos nativos, dos quais muitos foram arborizados nos últimos anos, houve redução na diversidade filogenética nas áreas plantadas, o que demonstra o empobrecimento taxonômico das comunidades de aves. Para esses autores o plantio de árvores pra fins econômicos em ecossistemas campestres pode representar uma ameaça futura para a manutenção de espécies de aves evolutivamente distintas, bem como para espécies exclusivas de ambientes campestres, as quais se mostraram evolutivamente incapazes de colonizar plantações arbóreas. Entre as medidas mitigadoras quanto ao impacto da eucaliptocultura sobre a biodiversidade destacam-se: implantação da monocultura do eucalipto em áreas apenas já convertidas ou degradadas (Jacoboski et al., 2019); realização de plantios de enriquecimento ou de reconstituição da flora em áreas de preservação permanente e reservas legais para a melhoria da capacidade de suporte dos remanescentes vegetais nativos e para recuperação das funções e serviços ambientais; promoção da recuperação ambiental com o plantio de espécies típicas da região; usar máquinas e equipamentos com níveis de ruído de acordo com as normas vigentes; e limitar a velocidade dos veículos nas redes viárias da eucaliptocultura (Rodrigues et al., 2021).

A utilização de produtos químicos para a manutenção da monocultura é outro aspecto preocupante. Nesta monocultura faz-se adubação, uso de biocidas na produção de mudas, controle de formigas cortadeiras, pragas e doenças o que ocasiona contaminação do solo, do ar (Crous et al., 2010) e cursos d’água superficial e água subterrânea; impacto às espécies não-alvo e à fauna polinizadora; eutrofização dos corpos d'água; danos à microbiota do solo e redução da capacidade de suporte para a fauna silvestre (Rodrigues et al., 2021) e o uso exacerbado de agrotóxico traz sérios riscos à saúde de trabalhadores e consumidores, provocando doenças graves e até mesmo a morte (Porto et al., 2012; Vechi et al., 2018; Basso et al., 2021; Ruths et al., 2021). O dossiê realizado pela Associação Brasileira de Saúde Coletiva sobre agrotóxicos, em 2015, mostra que uma área de 600 mil hectares recebe cerca de 5.400 litros de glifosato ao longo dos 7 anos de desenvolvimento da árvore. $\mathrm{O}$ documento também destaca a utilização de produtos à base de sulfuramida, utilizados para o controle de formigas, os quais integram a lista de substâncias proibidas pela certificadora internacional FSC (Forest Stewardship Council) (Carneiro et al., 2015). No Brasil as iscas contendo sulfuramida são utilizadas em grandes quantidades e oferecem riscos a organismos não 
alvos (Ramos et al., 2003). Para tentar mitigar os impactos negativos de fertilizantes e agrotóxicos devem ser adotadas as seguintes medidas: adoção de manejo integrado de pragas; uso de agrotóxicos na dose recomendada por profissional habilitado; restrição de pulverização aérea próximo a áreas de recargas e corpos d’água; e, no caso de uso de agrotóxicos, dar preferência àqueles com menor tempo de degradação do seu princípio ativo e aplicação em condições ideais de precipitação e vento, com uso de EPIs pelos trabalhadores (Rodrigues et al., 2021).

Ainda no contexto dos problemas socioambientais estão aqueles relacionados aos problemas sociais envolvendo comunidades de pequenos produtores (Mosca, 2008; Vechi et al., 2018). A aquisição de terras para implantação do cultivo florestal resulta em modificação da estrutura fundiária local, com possibilidade de êxodo rural (Rodrigues et al., 2021) e diminuição de produção e oferta de produtos essenciais para a alimentação da população local, oriundos, na maioria das vezes, da agricultura familiar. Um grupo de camponeses de uma cidade do Mato Grosso do Sul considera o monocultivo de eucalipto um obstáculo para o desenvolvimento de suas atividades no campo, uma vez que lavouras são perdidas por conta da pulverização de agrotóxicos nos eucaliptais, alterações na dinâmica das comunidades rurais e desequilíbrio biológico (Lelis \& Avelino Jr., 2016). Dentre as consequências da territorialização do capital, viabilizada pela alteração na posse e uso da terra e vinculada ao aumento do cultivo de eucalipto pelas empresas de celulose, está a expulsão de várias famílias (funcionários assalariados de fazendas, parceiros, meeiros, arrendatários) do campo para a cidade (Botelho et al., 2012; Vechi et al., 2018).

A implantação de uma monocultura pautada em um modelo totalmente dependente de fatores externos, desde aquisição de mudas, insumos agrícolas, comercialização e variações em bolsas de valores, não assegura nenhuma melhoria de vida para os trabalhadores locais. Ao contrário, as monoculturas com espécies exóticas em grandes extensões de terra, mantém a estrutura fundiária (com subsídio no latifúndio, desigualdade social e concentração de riqueza) e conduz a sérios conflitos, que tenderão a ser cada vez mais marcantes, seja pelo uso de recursos escassos, pela posse da terra ou, ainda, pela própria perda da identidade sociocultural local (Sell et al., 2011; Baratelli et al., 2020). Os problemas sociais como conflitos gerados por disputa de terras, extrativismo, desmatamento de áreas de conservação e falta de água para abastecer municípios e pequenos produtores também são observados com o crescimento da produção de eucalipto (Nobre et al., 2012; Vechi et al., 2018).

Em regiões de Minas Gerais e também no Maranhão, as quais apresentam períodos extensos de até cinco meses de seca, o acesso à água tem sido comprometido por conta da retirada indiscriminada de água dos poucos rios e aguapés da região para o plantio de eucalipto. Além disso, os conflitos causados pela disputa por terras de uso coletivo por quilombolas e camponeses também são comuns nessa região. As áreas de vegetação nativas povoadas por estas comunidades tradicionais estão ameaçadas com a formação de ilhas cercadas por plantas exóticas, sendo um dos problemas ambientais o isolamento das populações nativas da flora, o que compromete o extrativismo (Barros et al., 2011).

A pesquisa de Ramos et al. (2000) abrange diversos relatos de quilombolas, indígenas e trabalhadores vítimas dos problemas causados em decorrência da implantação de grandes áreas de eucalipto e também pelas empresas que processam a matéria-prima. Nos relatos são feitas denúncias que vão de problemas ambientais que alteram o modo de vida dos nativos à falta de condições de trabalho e maus tratos nas empresas.

Na cartilha organizada pela ONG Repórter Brasil, em 2011, os autores relatam que a expansão da monocultura de eucalipto e pinus no Brasil está intrínseca à denúncias e flagrantes de violação dos direitos trabalhistas e humanos. Isso contribui para que os nomes dos produtores destas árvores exóticas estejam presentes com frequência na lista de trabalho escravo. Essas denúncias acontecem devido a problemas como a falta de programas para a prevenção de acidentes, expondo os trabalhadores a riscos constantes em maquinários pesados e a agrotóxicos, que além de acidentes podem levar ao desenvolvimento de doenças crônicas (Barros et al., 2011). 
Silva et al., (2010) realizaram uma análise, através de entrevistas, acerca dos impactos socioeconômicos do cultivo de eucalipto em um município do Rio Grande do Sul. Segundo eles a produção de eucalipto cresceu no município por incentivo da prefeitura e cooperativa da cidade. Como a produção do eucalipto demora para ser efetivada, carece de menos mão de obra e o retorno financeiro é demorado. Isso ocasionou diminuição do trabalho para as famílias no campo, e, consequentemente, contribuiu para o aumento no êxodo rural. A pesquisa destaca também que o crescimento na produção de eucalipto gerou conflitos, pois, as árvores sombreiam as culturas vizinhas, prejudicando a produção de outras atividades econômicas no entorno, e consistiu em boa fonte de renda e acúmulo de capital para empresários. Em um estudo feito em comunidades da Etiópia, Zerga (2015) relata que as desvantagens trazidas pelo eucalipto, como a redução da produção de culturas alimentares por conta da diminuição de área para cultivo, sombreamento e efeitos alelopáticos de eucalipto, são ofuscadas pelo retorno financeiro.

Entre as medidas mitigadoras quanto aos impactos negativos da eucaliptocultura sobre a vida da população local estão: realizar na íntegra o cumprimento do zoneamento territorial municipal no que tange aos plantios do eucalipto; criar novas vagas de emprego e gerar estabilidade, por meio de alocação da mão-de-obra em diferentes operações da monocultura do eucalipto, priorizando os trabalhadores locais (Rodrigues et al., 2021); e fornecer condições para os trabalhadores locais atuarem nas atividades de eucaliptocultura através de cursos de capacitação.

A capacidade inflamável do eucalipto é outro ponto que gera preocupação. Em um incêndio ocorrido em Portugal em 2003, na Tapada Nacional de Mafra, o eucalipto foi o responsável pelo prejuízo. A área citada era composta, na época, por grande diversidade, incluindo árvores nativas e exóticas como eucalipto. Durante o incêndio foi observado que as árvores "preferidas" pelo fogo eram de eucalipto e $90 \%$ da área que era composta apenas por eucalipto foi consumida pelo fogo (Catry et al., 2007). O teor de lignina e a presença de materiais extrativos inflamáveis como óleos, resinas e ceras, especialmente quando em maiores quantidades, como nas plantas adultas, aumentam a combustibilidade e o poder calorífico das árvores (Burger et al., 1991). Essas características são apresentadas pelo eucalipto. A composição da madeira do eucalipto, com enfoque energético, contém grande quantidade de lignina com pouca variação quanto à idade, bem como a presença de óleos essenciais que são abundantes em suas folhas, compostos que favorecem o potencial energético (Santana, 2009; Garcia et al., 2021). O eucalipto apresenta capacidade de queima rápida e produz grande quantidade de biomassa, como folhas e cascas altamente inflamáveis, que na presença de ventos fortes pode projetar material incandescente a quilômetros de distância. O fogo provoca diversas alterações no ambiente, tanto na estrutura quanto na dinâmica e funcionalidade do ecossistema. No entanto, as espécies de eucalipto apresentam adaptações ao fogo, com boa resistência e capacidade de regeneração rápida, favorecidas pelo fato de não apresentarem consumidores (Catry et al., 2007), recuperando rapidamente a produção de biomassa que favorecem o risco de um novo incêndio (Anchaluisa et al., 2013). Os brotos iniciais do eucalipto têm vantagens por não sofrerem com a herbivoria, a qual ocorre em espécies nativas e estas são impedidas de regenerar.

Numa tentativa de diminuir os impactos da eucaliptocultura quanto aos incêndios, devem ser adotadas as seguintes medidas: ter equipes de ronda qualificadas para realizarem o monitoramento das áreas nos períodos mais secos; instalar torres de observação com equipe atuando em período integral; realizar o monitoramento de possíveis focos de incêndio por meio de drones; possuir obrigatoriamente uma brigada de incêndio devidamente equipada e qualificada (Rodrigues et al., 2021); e realizar a manutenção dos aceiros no entorno tanto da monocultura do eucalipto quanto das áreas de vegetação nativa e de divisa com as propriedades rurais.

As modificações, de ordem natural ou artificial da cobertura vegetal de bacias hidrográficas, influenciam nas variações do ciclo hidrológico, produzindo os mais variados impactos sobre o ambiente e a disponibilidade dos recursos hídricos (Tucci et al., 1997). Inerente ao ciclo hidrológico, a atividade de eucaliptocultura resulta em aumento da carga de sedimentos transportada pelas águas pluviais; assoreamento de corpos d’água; alteração da qualidade da água e dos 
ecossistemas aquáticos à jusante com impacto à fauna aquática e uso conflitivo da água (Rodrigues et al., 2021). A eucaliptocultura é uma monocultura de rápido crescimento, com retirada da biomassa árborea de forma sistemática e por cortes rasos, o que culmina em desequilíbrio nutricional, diferente de uma floresta nativa, de área não perturbada, onde os nutrientes introduzidos no ecossistema pela chuva e pelo intemperismo geológico estão em equilíbrio com os nutrientes perdidos para os rios e lençol freático (Câmara, 1999).

A água é o alimento que a planta mais necessita. Como os estômatos precisam ficar abertos para a planta se alimentar de gás carbônico e de oxigênio, a água se perde com facilidade por transpiração. Por essa razão, atribui-se ao eucalipto a fama de grande consumidor de água do solo. A faixa de evapotranspiração de florestas de eucalipto está entre 800 a $1200 \mathrm{~mm} /$ ano. Isso significa que plantar florestas de eucaliptos onde chove menos que $800 \mathrm{~mm}$ por ano dependerá de encontrar as espécies adaptadas a isso, e não se pode esperar grandes produtividades (Foelkel, 2005).

O consumo de água durante o desenvolvimento do eucalipto varia de acordo com a região onde a plantação está inserida (Tadeu \& Sinisgalli, 2014). Em relação à quantidade de água consumida é necessário considerar as interferências zonais, pois, as plantas respondem de forma diferente de acordo com a disponibilidade de recursos (Mosca, 2008). O sistema radicular é responsável por parte do consumo de água do solo, e, no caso do eucalipto, o tamanho e capacidade de crescimento em profundidade são variáveis de espécie para espécie e por fatores ambientais (Lima, 1996). Em solos que não apresentam nenhum impedimento rochoso, camadas compactadas e nem lençol freático superficial as raízes jovens podem crescer rapidamente, atingindo 1,5 a 2 metros de profundidade e realizando a coleta de água ao longo do seu perfil (Foelkel, 2005).

Para Oliveira et al. (2002) a plantação de eucalipto é altamente impactante aos recursos hídricos, ocasionando a diminuição da recarga de água subterrânea, quando comparada à vegetação nativa do Cerrado. Isso se deve à dificuldade em manter o equilíbrio da demanda evapotranspirativa por ser espécie exótica e não adaptada à manutenção do equilíbrio hídrico local. O equilíbrio hídrico depende da interação entre a evapotranspiração e o volume pluviométrico (Vital, 2007; Cavalcante \& Mendes, 2012). A redução da recarga de água subterrânea ocorre quando o consumo de água pela floresta é maior que o volume de chuvas. No Brasil o volume de água evapotranspirado pelas plantações de eucalipto é inferior ao de precipitação pluviométrica nas regiões onde se concentram as maiores áreas de produção. Assim, os impactos sobre os lençóis freáticos devem ser analisados caso a caso, pois, o consumo de água pode variar dependendo da localização da plantação de eucalipto em relação à bacia hidrográfica. Se o plantio ocorrer em áreas como as zonas ripárias, os eucaliptos consomem muita água, por conta da maior disponibilidade, e, consequentemente, podem gerar impactos sobre os lençóis freáticos (Vital, 2007).

A cobertura florestal tem grande importância para garantir a chegada da água ao solo. Durante a precipitação da chuva em uma floresta a água pode cair diretamente no solo, através de aberturas no dossel ou ficar interceptada na cobertura do dossel. Dessa maneira a água chega ao solo escoando entre os galhos, folhas e troncos (Consensa, 2012). Um fator considerado importante nesse processo é a densidade populacional, a qual influencia na quantidade de água do solo, uma vez que a precipitação pluviométrica interna é menor quando os espaçamentos entre as plantas são menores (Leite et al., 1999; Amaral et al., 2020). Esse processo também interfere na qualidade do solo, visto que plantações florestais, especialmente em solos já degradados, carecem da água das chuvas para a adição de nutrientes e a ciclagem bioquímica, essenciais para a manutenção da produtividade ao longo do tempo (Câmara, 1999). Além disso, o carreamento, a entrada e a deposição de sedimentos de menor fração granulométrica devido ao uso da terra no entorno das áreas ripárias estão entre os impactos adversos mais importantes sobre os sistemas aquáticos, ocasionando a redução da diversidade biológica desses ambientes, incluindo nascentes (Amaral et al., 2020).

Comparando um eucaliptal e um fragmento de Mata Atlântica constatou-se que na floresta de eucalipto mais água da chuva chega até o solo, fato explicado pelo índice de área foliar que é maior na Mata Atlântica, fazendo com que uma maior quantidade de água seja interceptada pela copa. No entanto, a chegada de mais água no solo provoca dois efeitos no eucaliptal: 
o primeiro é que mais água pode estar disponível no solo, bem como no lençol freático; e o segundo é que mais água caindo no solo pode aumentar a erosão (Vital, 2007).

Além do dano ao equilíbrio hídrico, as alterações provocadas no entorno de lagos, com a substituição da vegetação natural para a de eucalipto, comprometem a qualidade das águas, afetando a biota aquática, uma vez que as folhas de eucalipto liberam compostos naturais durante a decomposição (Abelho et al., 1996). Uma alta concentração de fenóis é observada no início do processo de decomposição do eucalipto. Isso contribui para um retardamento da decomposição, pois, dificulta a colonização por microrganismos e depois por invertebrados (Trevisan et al., 2007). Elevados teores de lignina e compostos aromáticos (como no caso da estrutura celular de eucaliptos) conferem ao material alta resistência, dificultando a penetração dos organismos do solo, enquanto elevados teores de carboidratos solúveis ou celulose promovem menor resistência, favorecendo a ação dos detritívoros (Moreira \& Siqueira, 2006). Os polifenóis exercem efeito adstringente tornando o material mais resistente (Gonçalves, 1995), menos palatáveis aos invertebrados e quanto mais polifenol a folha contém mais tempo leva para decompor (Mason, 1980). Além disso, a presença de uma cutícula espessa nas folhas de eucalipto contribui para as baixas taxas de decomposição. Foi observado em microscópio eletrônico que os fungos só podem penetrar no mesófilo de folhas de eucalipto através dos estômatos e fissuras na cutícula cerosa (Canhoto et al., 1999).

As folhas de eucalipto dispersas na serapilheira, durante o período de chuvas são levadas para rios e lagoas através da lixiviação, e, entrando em contato com o ambiente aquático, liberam constituintes químicos, como os do óleo essencial. Logo, a prevalência desses no meio aquoso representa um risco potencial de efeitos prejudiciais aos organismos aquáticos (Abelho et al., 1996). Hack (2009) afirma que a presença de eucaliptais próximo a curso d'água contribui com o aumento da matéria orgânica e da quantidade de fenóis quando comparados a locais com vegetação nativa. Esse material é proveniente do processo de lixiviação dos resíduos do eucalipto e do processo de decomposição de suas folhas. Os compostos fenólicos presentes nas folhas de eucalipto são liberados na água por um processo de lixiviação e formação de poças temporárias em eucaliptais (Canhoto et al., 2007). A presença desses compostos compromete a qualidade da água e a sobrevivência dos organismos aquáticos. Abelho e Graça (1996) constataram que a biodiversidade de hifomicetos e insetos aquáticos diminuiu em cursos de água cercados por eucaliptos. Esses hifomicetos tem papel fundamental no processo de decomposição dos detritos, uma vez que são responsáveis pela colonização das folhas, deixando-as mais palatáveis para serem consumidas pelos detritívoros (Gessner et al., 1999).

Para mitigar os impactos da eucaliptocultura no ciclo hidrológico e nas zonas ripárias devem ser adotadas as seguintes estratégias: construir bacias de acumulação de águas pluviais associadas a lombadas e camalhões para evitar processos erosivos e assoreamento dos cursos d'água; reduzir a intensidade do controle do sub-bosque nos talhões limítrofes às áreas de maior relevância ecológica, como as de vegetação ripária; escolher e manejar de maneira ambientalmente adequada o sistema de plantio do eucalipto de acordo com as características biofísicas locais; planejar e construir as estradas de transporte da produção de eucalipto, considerando aspectos hidrográficos e hidrológicos; construir pavimento com resistência mecânica suficiente para vencer o peso dos veículos, com fundações resistentes, cobertura e canais adequados para receber e transporta a água das precipitações (Rodrigues et al., 2021); manter uma distância ecologicamente segura entre a monocultura do eucalipto e as áreas de vegetação ripária; contribuir para a manutenção da área de vegetação ripária nas proximidades da eucaliptocultura de forma a assegurar o equilíbrio ecológico nos ambientes naturais. Além disso, recomenda-se fortemente a atuação do comitê de bacia hidrográfica local e dos gestores públicos, além da gestão correta das atividades rurais e implantação contínua de ações no âmbito da educação ambiental (Fiorese, 2021). 


\section{Considerações Finais}

Na vanguarda de um crescimento verde, houve uma expansão da eucaliptocultura no Brasil na última década, principalmente em decorrência da mudança de hábitos dos consumidores, mercados e investidores em busca de produtos sustentáveis, diante da realidade das mudanças climáticas. Entretanto, a atividade de eucaliptocultura implica, assim como toda atividade econômica, em impactos socioambientais benéficos e adversos.

Os impactos benéficos da eucaliptocultura estão associados à economia, uma vez que ocorre a geração de empregos e impostos a partir da venda interna e exportação de produtos, como a madeira e celulose, e ao meio ambiente quanto à capacidade de fixação de $\mathrm{CO}_{2}$ e ao fato de preservar a floresta nativa para extração de matéria-prima.

Já os impactos adversos da eucaliptocultura, os quais se sobrepõem aos benéficos, se devem, principalmente ao fato de que a produção do eucalipto ocupa grandes áreas, resultando em empobrecimento da biodiversidade local, degradação ambiental e conflitos no meio rural e urbano. A identificação das características e condições de conservação ambientais no local onde é implantada a monocultura do eucalipto (como, proximidade de áreas de vegetação ripária, biodiversidade local, tipos de clima e de solo, declividade do terreno, disponibilidade hídrica da bacia hidrográfica), da estrutura fundiária préexistente e implementação de um conjunto de ações mitigadoras para cada impacto adverso está relacionada à gestão ambiental ecologicamente correta, na qual o conhecimento científico interdisciplinar aliado à tecnologia assume grande importância.

Espera-se que os resultados discutidos neste trabalho possam despertar novas reflexões sobre a eucaliptocultura no Brasil e direcione estudos futuros de forma a minimizar as lacunas do conhecimento existente. Neste viés, urge a necessidade da realização de pesquisas que considerem o panorama da distribuição da eucaliptocultura para cada um dos estados brasileiros de grande produção de eucalipto, associada às condições edafoclimáticas, sociais e políticas que subsidiem uma análise mais complexa e abrangente acerca dos impactos desta monocultura em cada um desses estados.

\section{Referências}

Abelho, M. \& Graça, M. A. S. (1996). Effects of eucalyptus afforestation on leaf litter dynamics and macroinvertebrate community structure of streams. $J$ Hydro, 324 (3), 195-204.

Afonso, R. \& Miller, D. C. (2021). Forest plantations and local economic development: Evidence from Minas Gerais, Brazil. Forest Policy and Economics, 133,102618 .

Aires, C. F. \& Pimenta, H. C. D. (2020). Práticas ambientais em laboratórios químicos universitários: uma revisão sistemática de literatura. Research, Society and Development, 9 (8), e378985490.

Amaral, P. H. M. do, Peixoto, S. D., Machado, M. M. D., Rocha, C. H. B. \& Alves, R. D. Caracterização granulométrica do sedimento de nascentes tropicais em áreas plantadas com eucalipto. Ciência Florestal, 30 (4), 1075-1084.

Amorim, V. S. S. de, Monteiro, K. M. S., Sousa, G. O., Damascena, J. F., Pereira, J. A. \& Moraes, W. S. (2021). Os benefícios ambientais do plantio de eucalipto: revisão de literatura. Research, Society and Development, 10 (11), e318101119604.

Anchaluisa, S. \& Suárez, E. (2013). Efectos del fuego sobre la estructura, microclima y funciones ecosistémicas de plantaciones de eucalipto (Eucalyptus globulus, Myrtaceae) en el Distrito Metropolitano de Quito, Ecuador. Avances, 5 (2), 14-23.

Andrade, E. N. (1928). A cultura do Eucalyptus. Typographia Brazil de Rothschild e Cia. 154p.

Antonangelo, A. \& Bacha, C. J. C. (1998). As Fases da Silvicultura no Brasil. Revista Brasileira de Economia, 52 (1), $207-238$.

Bacha, C. J. C. (2008). Análise da evolução do reflorestamento no Brasil. Rev. de Economia Agrícola, 55 (2), 5-24.

Baratelli, A. E. S., Medeiros, G. N. de \& Luiz, L. F. (2020). A expansão do eucalipto e a dinâmica da pecuária no município de Três Lagoas/MS. Revista Pegada, 21 (3), 161-182.

Barbieri, A., F., Guerra, C. B., Torres, H. G., Simões, R. F., Reis, A. V., Scliar, C., Abdo, R. O. O. \& Lins, S. E. B. (1997). Atividades antrópicas e impactos ambientais. In: Paula, J. A. Biodiversidade, população e economia: uma região de Mata Atlântica. UFMG. p. 271-344.

Barros, C. J. \& Campos, A. (2011). Deserto verde: os impactos do cultivo de eucalipto e pinus no Brasil. Repórter Brasil - Organização de Comunicação e Projetos Sociais. 14 p. 
Barros, K. N. N. O., Albuquerque, M. A. de \& Silva, J. A. A. da. (2020). Modelos simétricos transformados bayesianos para descrever o crescimento em altura de eucalyptus urophylla. Research, Society and Development, 9 (8), e820986448.

Basso, C., Siqueira, A. C. F. \& Richards, N. S. P. S. (2021). Impactos na saúde humana e no meio ambiente relacionados ao uso de agrotóxicos: Uma revisão integrativa. Research, Society and Development, 10 (8), e43110817529.

Bertola, A. (2013). Eucalipto - 100 anos de Brasil - "Falem mal, mas continuem falando de mim!". V\&M Florestal Ltda.

Bichel, A. \& Telles, T. S. (2021). Spatial dynamics of firewood and charcoal production in Brazil. Journal of Cleaner Production, $313,127714$.

Botelho, A. C., Almeida, J. G. \& Ferreira, M. G. R. (2012). O avanço dos “eucaliptais": análise dos impactos socioambientais em territórios camponeses no leste maranhense. Rev. Percurso, 4 (2), 79-94.

Brasil. (1970). Decreto-Lei no 1.134, de 16 de novembro de 1970. Altera a sistemática de incentivos fiscais concedidos a empreendimentos florestais.

Burger, L. M. \& Richter, H. G. (1991). Anatomia da madeira. Nobel. 154p.

Cabral, E. G., Barreira, S., Ferreira, M. E. \& Araújo, L. G. O. (2019). A silvicultura do eucalipto no estado de Goiás: um registro histórico via sensoriamento remoto. Pesquisa Florestal Brasileira, 39, e201801649, 1-15.

Câmara, C. D. (1999). Efeitos do corte raso de eucalipto sobre o balanço hídrico e a ciclagem de nutrientes em uma microbacia experimental, Dissertação (Mestrado) - Universidade de São Paulo, Piracicaba. 103p.

Cândido, B. M., Silva, M. L. N., Curi, N. \& Batista, P. V. G. (2014). Erosão hídrica pós-plantio em florestas de eucalipto na bacia do rio Paraná, no leste do Mato Grosso do Sul. Rev. Bras. Ciênc. Solo., 38 (5), 1565-1575.

Canhoto, C. \& Laranjeira, C. (2007). Leachates of Eucalyptus globulus in intermittent streams affect water parameters and invertebrates. Int Rev. Hydro, 92 (2), 173-182.

Canhoto, C. \& Graça, M. A. S. (1999). Leaf barriers to fungal colonization and sheredders (Tipula lateralis) consumption of decomposing Eucalyptus globulus. Microb. Ecol, 37, 163-172.

Cavalcante, R. B. L. \& Mendes, C. A. B. (2012). Modelagem do balanço hídrico em povoamentos de eucalipto sob diferentes manejos como auxílio ao gerenciamento do impacto hidrológico da atividade. Rev. Ambient. Água, 7 (1), 268-280.

Carneiro, F. F., Augusto, L. G. S., Rigotto, R. M., Friedrich, K. \& Búrigo, A. C. (2015). Dossiê ABRASCO: um alerta sobre os impactos dos agrotóxicos na saúde. São Paulo: Expressão Popular. 624 p.

Catry, F., Bugalho, M. \& Silva, J. (2007). Recuperação da floresta após o fogo: O caso da Tapada Nacional de Mafra. CEABN. 40p.

Cavenage, A., Moraes, M. L. T., Alves, M. C. A., Carvalho, M. A. C., Freitas, M. L. M. \& Buzetti, S. (1999). Alterações nas propriedades físicas de um Latossolo Vermelho-Escuro sob diferentes culturas. Revista Brasileira de Ciência do Solo, 23 (4), 997-1003.

Chaves, E., Santos, C. V. dos, Ramos, P. V., Inda Junior, A. V. \& Caner, L. (2021). Propriedades físicas de um Argissolo após 17 anos de florestamento com Eucalyptus spp. Research, Society and Development, 10 (5), e58610514424.

Consensa, C. B. (2012). Precipitação pluviométrica e interna em povoamentos de Eucalyptus spp. em Rosário do Sul, RS. Dissertação (Mestrado) Universidade Federal de Santa Maria, Santa Maria. 95p.

Correa, A. P. M., Lima, A. P. L. de, Lima, S. F. de, Silva, W. G. da, Stolle, L.\& Silva, A. A. P. da. (2020a). Efeito do espaçamento sobre o crescimento e produção de eucalipto de rápida rotação aos 24 meses de idade. Research, Society and Development, 9 (6), e49963404.

Correa, H. C. R., Florentim, E. T. S., Monteiro, F. D. N., Falcão, K. S. \& Panachuki, E. (2020b). Zoneamento Agroclimático para espécies do Gênero Eucalyptus no Estado do Mato Grosso do Sul. Research, Society and Development, 9 (12), e4691210741.

Costa, B. C., Suzuki, P. M., Barros, W. S., Fróes Júnior, P. S. M., Rebello, F. K. \& Santos, M. L. dos. (2020). Análise da conjuntura do mercado de madeira de reflorestamento no Estado do Pará. Research, Society and Development, 9 (11), e80491110578.

Costa, C. D. O., Alves, M. C., Sousa, A. P., Silva, H. R., González, A. P., \& Avalos, J. M. M. (2016). Produção e deposição de sedimentos em uma sub-bacia hidrográfica com solos suscetíveis à erosão. Irriga, 21(2), 284-299.

Costa, E. V. S., Pereira, M. P. C. F., Silva, C. M. S., Pereira, B. L. C., Rocha, M. F. V. \& Carneiro, A. C. O. (2019). Torrefied briquettes of sugar cane bagasse and Eucalyptus. Revista Árvore, 43 (1), e430101.

Crous, K.Y., Zaragoza-Castells, J., Löw, L., Tissue, M.G., Barton, C.V. M., Gimeno, T. E. \& Atkin, O. K. (2010). Seasonal acclimation of leaf respiration in Eucalyptus saligna trees: impacts of elevated atmospheric $\mathrm{CO}_{2}$ and summer drought. Global Change Biology, 17 (4), $1560-1576$.

Ebling, E. D., Reichert, J. M., Pelaez, J. J. Z., Rodrigues, M. F., Valente, M. L., Cavalcante, R. B. L., Reggiani, P. \& Srinivasan, R. (2021). Event-based hydrology and sedimentation in paired watersheds under commercial eucalyptus and grasslands in the Brazilian Pampa biome. International Soil and Water Conservation Research, 9, $180-194$.

Embrapa (Empresa Brasileira de Pesquisa Agropecuária). (2019). Perguntas e Respostas - Portal Embrapa. Embrapa.br. https://www.embrapa.br/pt/web/portal/florestas/transferencia-detecnologia/eucalipto/perguntas-e-respostas.

Farinaci, J. S., Ferreira, L.C. \& Batistella, M. (2013). Forest transition and ecological modernization: eucalyptus forestry beyond good and bad. Ambient. soc., $16(2), 25-46$ 
Fernandes, P. R. S., Ferreira, C. C. B., Damascena, J. F., Silva, F. R. da, Lima, Í. C. S., Barbosa, R. S. \& Santos, A. C. dos (2021). Diagnóstico da relação de degradação de solo e planta em área de cultivo de Eucalyptus urophylla com a presença de térmitas e formigas. Research, Society and Development, 10 (5), e49610515240.

Ferreira, D. H. A. A., Leles, P. S. S., Oliveira Neto, S. N., Paula, T. R., Coutinho, R. P. \& Silva, R. L. (2017). Crescimento e produção de eucalipto na região do Médio Paraíba do Sul, RJ. Floresta e Ambiente, 24, e00131315.

Ferreto, D. O. C., Reichert, J. M., Cavalcante, R. B. L. \& Srinivasan, R. (2021). Water budget fluxes in catchments under grassland and Eucalyptus plantations of different ages. Canadian Journal of Forest Research, 51 (4).

Fiorese, C. H. U. (2021). Land use and occupation in the Fundaça Stream subbasin, Espírito Santo, Brazil. Revista Agrogeoambiental, 13 (1), 82 - 96.

Flores, T. B., Alvares, C. A., Souza, V. C. \& Stape, J. L. 2016. Eucalyptus no Brasil: Zoneamento climático e guia de identificação. IPEF. 448p.

Foelkel, C. (2005). Minerais e nutrientes das árvores dos eucaliptos: Aspectos ambientais, fisiológicos, silviculturais e industriais acerca dos elementos inorgânicos presentes nas árvores. In: Foelkel, C. Eucalyptus Newsletter. p. 1-133.

Fritzsons, E. \& Parron, L. M. (2016). Plantações florestais comerciais e a água. In: Embrapa Florestas (Org). Plantações florestais: geração de benefícios com baixo impacto ambiental. Colombo: Embrapa, p. 37-46.

Gama-Rodrigues, E. F. \& Gama-Rodrigues, A. C. (2008). Biomassa microbiana e ciclagem de nutrientes. In: Santos, G. A., Silva, L. S., Canellas, L. P. \& Camargo, F. O. (Eds.). Fundamentos da matéria orgânica do solo: ecossistemas tropicais e subtropicais. (2ed.). Metrópole Editora Ltda. 1-12.

Garcia, H. V. S., Furtini, A. C. C., Brito, F. M. S., Santos, C. A. dos, Ribeiro, D. A., Guimarães Júnior, J. B. \& Mendes, L. M. (2021). Desempenho de painéis de madeira laminada colada cruzada constituídos com eucalipto, seringueira e bambu. Research, Society and Development, 10 (8), e33210817181.

Gessner, M. O., Chauvet, E. \& Dobson, M. (1999). A perspective on leaf litter breakdown in streams. Oikos, 85 (2), $377-384$.

Gonçalves, J. L. M. (1995). Efeito do cultivo mínimo sobre a fertilidade do solo e ciclagem de nutrientes. Anais... In: $1^{\circ}$ Seminário sobre cultivo mínimo do solo em florestas, Curitiba, Instituto de Pesquisas e Estudos Florestais. 43 - 60.

Gualberto, A. V. S., Cunha, J. R. da, Vogado, R. F., Leite, L. F. C., Nunes, L. A. P. L. \& Souza, H. A. de. (2021). Epigean fauna in no-till systems, pasture, Eucalyptus and native savanna in Uruçuí, Piauí, Brazil. Revista Brasileira de Ciências Agrárias, 16 (3), e8782.

Guo, M., Song, W. \& Buhain, J. (2015). Bioenergy and biofuels: history, status, and perspective. Renew. Sustain. Energy Rev., $42,712-725$.

Hack, C. S. (2009). Monitoramento da qualidade de água e caracterização de resíduos florestais em uma microbacia sob a influência do cultivo de eucaliptos no sul do Brasil. Dissertação (Mestrado) - Pontifícia Universidade Católica do Rio Grande do Sul, Porto Alegre. 101p.

Hasse, G. (2006). Eucalipto: histórias de um imigrante vegetal. JÁ Editores. 127p.

IBÁ (Indústria Brasileira de Árvores). (2021). Relatório Anual Ibá 2021.

Jacoboski, L. I., Luza, A. L., Paulsen, R. K., Pezda, A.M. \& Hartz, S. M. (2019). The effects of grassland ecosystem afforestation on avian phylogenetic diversity, taxonomic diversity and evolutionary distinctiveness. Acta Oecologica, 99, 103449.

Jesus, G. L., Almeida, L. F. J., Santos, A. S., Leite, F. P. \& Neves, J. C. L. (2015). Produtividade do eucalipto, atributos físicos do solo e frações da matéria orgânica influenciadas pela intensidade de tráfego e resíduos de colheita. R. Bras. Ci. Solo, 39, 1190-1203.

Juvenal, T.L. \& Matos, R. L. G. (2002). O setor florestal no Brasil e a importância do reflorestamento. BNDES Setorial, 16: 3-30.

Kudlavicz, M. (2014). A territorialização da monocultura do eucalipto: um estudo da região leste do Mato Grosso do Sul. Novas Edições Acadêmicas. 208p.

Larrañaga, A., Basaguren, A. \& Pozo, J. (2009). Impacts of Eucalyptus globulus Plantations on physiology and population densities of invertebrates inhabiting Iberian Atlantic Streams. Hydrobiology, 94 (4), 497-511.

Leite, L. F. C. (2002). Compartimentos e dinâmica da matéria orgânica do solo sob diferentes manejos e sua simulação pelo Modelo Century. Tese (doutorado em solos e nutrição de plantas) - Universidade Federal de Viçosa.

Leite, F. P., Barros, N. F., Novais, R. F., Baretta, D. \& Vieira, H. C. (1999). Relações hídricas em povoamento de eucalipto com diferentes densidades populacionais. R. Bras. Ci. Solo, 23, 9-16.

Lelis, L. R. M. \& Avelino Jr, F. J. (2016). Territorialização do complexo eucalipto-celulose-papel e resistência camponesa em Três Lagoas - MS. Cam. Geo., 17 (58), 81-102.

Lenz, A. M., Rosa, H. A., Mercante, E., Maggi, M. F., Mendes, I. D., Cattani, C. E. V., Johann, J. A., Ferruzzi, Y. \& Gurgacz, F. (2019). Expansion of eucalyptus energy plantations under a Livestock-Forestry Integration scenario for agroindustries in Western Paraná, Brazil. Ecological Indicators, 98, 39-48.

Lima, W. P. (1996). Impacto ambiental do eucalipto. São Paulo: USP. 301 pp.

Lino, V. V. R., Sousa, G. O., Costa, N. B., Oliveira, A. B. C. \& Leite, M. R. P. (2020). Efeito alelopático do extrato aquoso de Eucalyptus urophylla em sementes de milho e feijão-caupi. Research, Society and Development, 9 (8), e335985724.

Mason, C. F. (1980). Decomposição. E.P.U. 63p. 
Medeiros, G., Florindo, T., Talamini, E., Fett, A. \& Ruviaro, C. (2020). Optimising tree plantation land use in Brazil by analysing trade-offs between economic and environmental factors using multi-objective programming. Forests, 11, 723.

Moledo, J. C., Saad, A. R., Dalmas, F. B., Arruda, R. O. M. \& Casado, F. (2016). Impactos ambientais relativos à silvicultura de eucalipto: uma análise comparativa do desenvolvimento e aplicação no plano de manejo florestal. Geociências, 35 (4), 512-530.

Montebello, A. E. S. \& Bacha, C. J. C. (2013). Análise do processo de configuração desigual do setor de celulose e papel no Brasil. Pesquisa \& Debate, 23 (2) (44), 267-294.

Monteiro, N. F., Lima, H. M. R., Silva, F. L. da, Sousa, F. C. A., Silva, W. C. da, Reis, L. C. M., Pimentel, A. C. C., Furtado, D. R., Rodrigues, A. C. E., Rodrigues, R. P. S., Alves, A. M. M., Rodrigues, J. P. P. \& Monteiro, A. L. (2021). Atividade do óleo essencial de Eucalyptus Globulus no controle de bactérias da cavidade oral. Research, Society and Development, 10 (14), e60101420387.

Moreira, F. M. S. \& Siqueira, J. O. (2006). Microbiologia e Bioquímica do solo. UFLA. 729p.

Morosini, M. C. (2015). Estado de conhecimento e questões do campo científico. Educação - Revista do Cento de UFSM, 40 (1), $101-116$.

Mosca, A. A. O. (2008). Avaliação dos impactos ambientais de plantações de eucalipto no cerrado com base na análise comparativa do ciclo hidrológico e da sustentabilidade da paisagem em duas bacias de segunda ordem. Tese (Doutorado) - Universidade de São Paulo, São Paulo. 256p.

Nobre, B. A. \& Leite, M. E. (2012). Monocultura do eucalipto, impacto ambiental e conflito na bacia do Canabrava, no norte de Minas Gerais. Rev VITAS, 2 (4), $1-8$.

Oliveira, F. R., Menegasse, L. N. \& Duarte, U. (2002). Impacto ambiental do eucalipto na recarga de água subterrânea em área de cerrado, no médio Vale do Jequitinhonha, Minas Gerais. Anais... In: XII congresso brasileiro de águas subterrâneas, Abas, São Paulo.1 - 10.

Pereira, J. C. D., Sturion, J. A., Higa, A. R., Higa, R. C. V. \& Shimizu, J. Y. (2000). Características da madeira de algumas espécies de eucalipto plantadas no Brasil. Colombo: Embrapa Florestas. 113p.

Poore, M. E. D. \& Fries, C. (1985). The ecological effects of eucalyptus. FAO. 97p.

Ramalho, M. A. S., Santos, B., Ramalho, D. F., Cunha, S. M. D. da, Anjos, R. M. dos, Oliveira, H. M. B. F. de, Sousa, A. P. de, Oliveira Filho, A. A. de. (2020). Atividade antiaderente dos óleos essenciais de Eucalyptus globulus e Eucalyptus citriodora contra cepas de Klebsiella pneumoniae. Research, Society and Development, 9 (7), e406974245.

Ramos, I., Carrene, R., Vinaixa, N. \& Cadena, C. (2000). Símbolos de un modelo destructivo: Pinos y Eucaliptos. Equador: Atopos. 137p.

Ramos, L. S., Marinho, C. G. S., Zanetti, R., Delabie, J. H. C. \& Schindwein, M. N. (2003). Impacto de iscas formicidas granulados sobre a mirmecofauna não-alvo em eucaliptais segundo duas formas de aplicacação. Neotropical Entomology, 32 (2), 231-237.

Reichert, J. M., Suzuki, L. E. A. S., \& Reinert, D. J. (2007). Compactação do solo em sistemas agropecuários e florestais: identificação, efeitos, limites críticos e mitigação. Tópicos em ciência do solo, 5, 49-134.

Rezende, J. B., Pereira, J. R. \& Botelho, D. D. (2013). Expansão da cultura do eucalipto nos municípios mineiros e gestão territorial. Cerne, 19 (1), 1-7.

Rodrigues, G. S. S. C., Ross, J. L. S., Teixeira, G., Santiago, O. R. P. L. \& Franco, C. (2021). Eucalipto no Brasil: expansão geográfica e impactos ambientais. Uberlândia: UFU. 178p.

Rosa, M. G. da, Santos, J. C. P., Brescovit, A. D., Mafra, A. L. \& Baretta, D. (2018). Spiders (Arachnida: Araneae) in Agricultural Land Use Systems in Subtropical Environments. Revista Brasileira de Ciência do Solo, 42, e0160576.

Ross, J. L. S. (2021). Sistemas ambientais naturais e núcleos de concentração de eucaliptos. In: Rodrigues, G. S. S. C., Ross, J. L. S., Teixeira, G., Santiago, O. R. P. L. \& Franco, C. Eucalipto no Brasil: expansão geográfica e impactos ambientais. Uberlândia: UFU. 46-65.

Ruths, J. C. \& Simch, F. B. D. L. (2021). Vigilância em saúde de populações expostas a agrotóxicos: revisão de escopo. Research, Society and Development, $10(2)$, e11410212330.

Salim, N., Rahman, M. N. A., \& Wahab, D. A. (2019) A systematic literature review of internal capabilities for enhancing eco-innovation performance of manufacturing firms. Journal of Cleaner Production, 209, 1445-1460.

Santana, W. M. S. (2009). Crescimento, produção e propriedades da madeira de um clone de Eucalyptus grandis e E. urophylla com enfoque energético, Dissertação (Mestrado) - Universidade Federal de Lavras, Lavras. 91p.

Santos, T. \& Trevisan, R. (2009). Eucaliptos versus bioma Pampa: compreendendo as diferenças entre lavouras de arbóreas e o campo nativo. In: Teixeira Filho, A. (Org.). Lavouras de Destruição: a (im)posição do consenso. Petolas: snt. 299-332.

Scolforo, J. R. (2008). O mundo eucalipto: os fatos e mitos de sua cultura. Mar de Ideias. 80 p.

Sell, J. K. \& Figueiró, A. S. (2011). Transformação da paisagem e impactos socioambientais no bioma Pampa. Revista da ANPEGE, 7 (8), $129-141$.

Silva, A. C. \& Costa, A. S. V. (2004). Decomposição de partes vegetativas de eucalipto (Eucalyptus grandis) submetidas a extratos de diferentes solos. RACAA, 2 (2), 11-20.

Silva, S. R., Barros, N. F., Costa, L. M., Mendonça, E. S., \& Leite, F. P. (2007). Alterações do solo influenciadas pelo tráfego e carga de um forwarder nas entrelinhas de uma floresta de eucalipto. Revista Brasileira de Ciência do Solo, 31 (2), 371-377. 
Silva, J. O. M. \& Marin, M. Z. (2010). Os impactos socioeconômicos do cultivo de eucalipto: o caso do município de Aratiba-RS. PERSPECTIVA, 34 (127), 113-122.

Souza, N. R. D., Junqueira, T. L. \& Cavalett, O. (2021). Opportunities and challenges for bioenergy-livestock integrated systems in Brazil. Industrial Crops and Products, 173, 114091.

Tadeu, N. D. \& Sinisgalli, P. A. A. (2014). Impactos hídricos da produção de madeira de eucalipto no trecho paulista da bacia hidrográfica do rio Paraíba do Sul. RCAAP, 1, 97-115.

Tassinari, D., Andrade, M. L. D., Dias, M. D., Martins, R. P., Rocha, W. W., Pais, P. S. A. M. \& Souza, Z. R. de. (2019). Soil compaction caused by harvesting, skidding and wood processing in eucalyptus forests on coarse-textured tropical soils. Soil Use Manage, $35,400-411$.

Teago, G. B. S., Oliveira, J. T. T. S., Vidaurre, G. B., Leite, F. P., Rosado, A. M., Moulin, J. C., Silva, J. G. M., Oliveira, J. C. L. de \& Silva, A. P. C. (2020). Impacto do cultivo misto nas propriedades das madeiras de acácia e eucalipto no Brasil. Research, Society and Development, 9 (4), e151943012.

Teixeira, E. C., Lima, A. P. L. de, Lima, S. F. de, Soratto, D. N., Ramos, K. V. \& Silva, W. G. da. (2020). Potencial energético da madeira de clones de eucalipto em diferentes espaçamentos. Research, Society and Development, 9 (7), e02973733.

Teixeira, G. \& Rodrigues, G. S. S. C. (2021). Trajetória geográfica da silvicultura em Minas Gerais. Mercator, 20, e20004,

Trevisan, A. \& Hepp, L. U. (2007). Dinâmica de componentes químicos vegetais e fauna associada ao processo de decomposição de espécies arbóreas em um riacho do norte do Rio Grande do Sul, Brasil. Neo Bio Conservation, 2 (1), 55-60.

Tsukamoto Filho, A. A., Couto, L., Neves, J. C. L., Passos, C. A. M. \& Silva, M. L. (2004). Fixação de carbono em um sistema agrissilvipastoril com eucalipto na região do cerrado de Minas Gerais. Agrossivicultura, 1 (1), 29-41.

Tucci, C. E. M. \& Clarke, R. T. (1997). Impacto das mudanças da cobertura vegetal no escoamento: revisão. RBRH, 2 (1), $135-152$.

Vechi, A. \& Magalhães Júnior, C. A. O. (2018). Aspectos positivos e negativos da cultura do eucalipto e os efeitos ambientais do seu cultivo. Rev. Valore, 1 (3), 495-506.

Vezani, F. M \& Mielniczuk, J. (2009). Uma visão sobre qualidade do solo. Revista Brasileira de Ciência do Solo, 33 (4), $743-755$.

Viana, M. B. (2004). O eucalipto e os efeitos ambientais do seu plantio em escala. Brasília: Biblioteca Digital da Câmara dos Deputados. 30p.

Vital, M. H. F. (2007). Impacto Ambiental de Florestas de Eucalipto. Rev BNDES, 14 (28), 235-276.

Zanzini, A. C. D., Silva, A. A. N., Pereira, C. Z., Santiago, W. T. V. \& Zanon, M. H. D. (2017). Composição de espécies de mamíferos de médio e grande porte em plantio de eucalipto e fragmentos de florestas nativas, no sudeste do Estado de Minas Gerais. Scientia Forestalis, 45 (116), $673-683$.

Zerga, B. (2015). Ecological impacts of Eucalyptus plantation in Eza Wereda, Ethiopia. IIJASS, 3 (4), 47-51.

Zolin, C. A., Matos, E. D., Magalhaes, C. A. D., Paulino, J., Lal, R., Spera, S. T. \& Behling, M. (2021). Short-term effect of a crop-livestock-forestry system on soil, water and nutrient loss in the CerradoAmazon ecotone. Acta Amazonica, 51 (2), 102 - 112. 